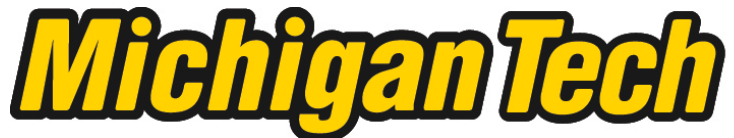 \\ Michigan Technological University Create the Future Digital Commons @ Michigan Tech
}

2014

\section{A Cost Analysis Of Carbon Dioxide Emission Reduction Strategies For New Plants In Michigan's Electric Power Sector}

Fei Li

Michigan Technological University

Follow this and additional works at: https://digitalcommons.mtu.edu/etds

Part of the Natural Resource Economics Commons

Copyright 2014 Fei Li

\section{Recommended Citation}

$\mathrm{Li}$, Fei, "A Cost Analysis Of Carbon Dioxide Emission Reduction Strategies For New Plants In Michigan's Electric Power Sector", Master's Thesis, Michigan Technological University, 2014.

https://doi.org/10.37099/mtu.dc.etds/817

Follow this and additional works at: https://digitalcommons.mtu.edu/etds

Part of the Natural Resource Economics Commons 


\title{
A Cost Analysis Of Carbon Dioxide Emission Reduction Strategies For New Plants In Michigan's Electric Power Sector
}

\author{
By
}

Fei Li

\begin{abstract}
A THESIS
Submitted in partial fulfillment of the requirements for the degree of MASTER OF SCIENCE

In Applied Natural Resource Economics
\end{abstract}

MICHIGAN TECHNOLOGICAL UNIVERSITY

2014

(C) 2014 Fei Li 
This thesis has been approved in partial fulfillment of the requirements for the Degree of MASTER OF SCIENCE in Applied Natural Resource Economics.

School of Business and Economics

Thesis Advisor: $\quad$ Mark C. Roberts

Committee Member: Garry A. Campbell

Committee Member: Min Wang

School Dean: $\quad$ Eugene R. Klippel 


\section{Table of Contents}

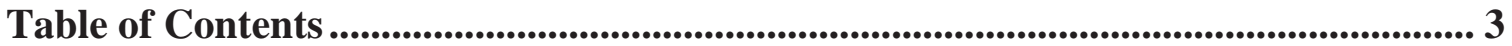

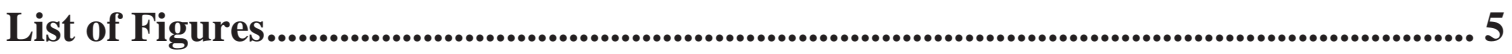

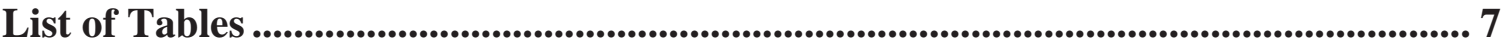

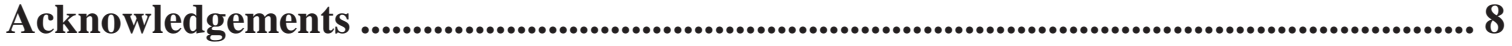

List of Abbreviations ..................................................................................................... 9

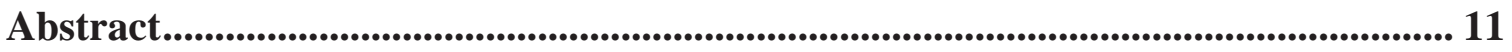

Chapter: 1 Introduction ............................................................................................................. 12

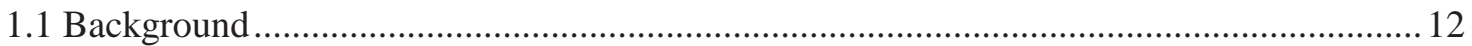

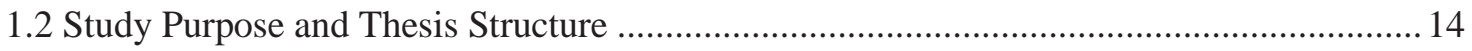

Chapter 2: Literature Review and Methodology .............................................................. 16

Chapter 3: Projecting Future $\mathrm{CO}_{2}$ Emission from Coal-Fired Power Plants in Michigan ............................................................................................................................ 19

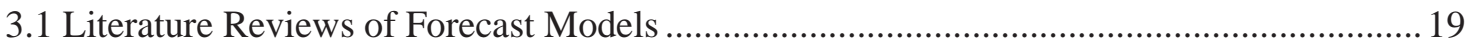

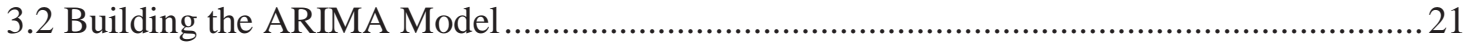

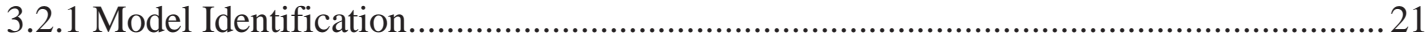

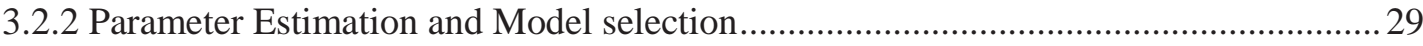

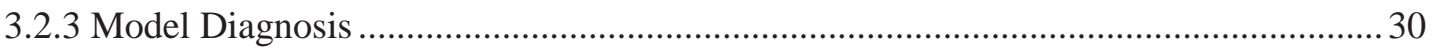

3.3 Projecting Future $\mathrm{CO}_{2}$ Emissions from Coal-fired Power Plant in Michigan...................... 34

Chapter 4: Calculating CO 2 Emission Reduction Cost .................................................... 36

4.1 $\mathrm{CO}_{2}$ Emission Reductions under Different Scenarios...................................................... 36

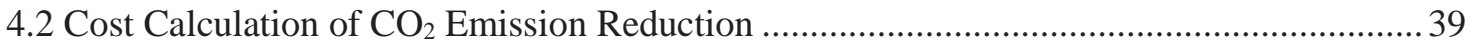

Chapter 5: Discussion ........................................................................................... 51

5. 1 The Impacts of the PTC on the Cost of $\mathrm{CO}_{2}$ Emission Reduction Technologies ...............52

5.2 The Impacts of the Intermittency of Renewable Energy ..................................................59

Chapter 6 Conclusion ......................................................................................... 67

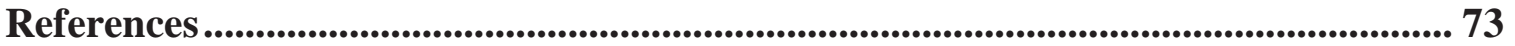

Appendices......................................................................................................................... 77

Appendix A: Coal Consumption for Electricity Generation from 1960 to 2011 in Michigan... 77 
Appendix B: The Linear Regression Results of Coal Consumption against Year from Using the R Program

Appendix C: Residual Plot Against the Independent Variable from the Linear Regression Approach.

Appendix D: Q-Q Plot for the Residuals of Linear Regression Approach 80

Appendix E: The R Outputs of Durbin-Waton Test for the Residuals of the Linear Regression

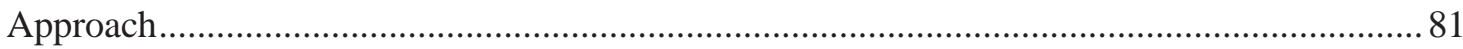

Appendix F: Sample ACF for the Standardized Residuals of the Linear Regression Model ....82 Appendix G: The R Outputs of Dickey-Fuller Test of the Fist difference of Coal Consumption for Electricity Generation in Michigan

Appendix H: The R Outputs of Durbin-Waton Unit Root Test of the Second Difference of Coal Consumption for Electricity Generation in Michigan .83

Appendix I: The R Outputs of Estimating the Parameters of ARIMA $(2,2,1)$ by Maximum Likelihood Method...

Appendix J: The R Outputs of Estimating the Parameters of ARIMA $(0,2,1)$ by Maximum

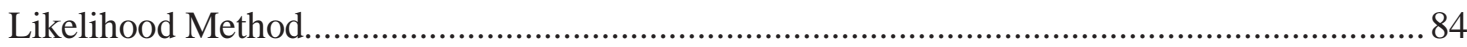

Appendix K: The R Outputs of the auto.arima Function to Find the Appropriate ARIMA Model.

Appendix L: The R outputs of Box-Ljung Test for the Residuals of ARIMA $(0,2,1)$ Model .84 Appendix M: The R Outputs of the Predicted Values, 95\% Prediction Intervals, and Standard Errors of Prediction. 85 


\section{List of Figures}

Figure 1: Coal consumption for electricity generation from 1960 to 2011 in

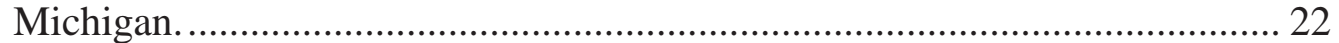

Figure 2: Sample ACF for Time Series Data of Coal Consumption in Michigan .... 24

Figure 3: Sample ACF Computed on the First Difference of Time Series Data of

Coal Consumption in Michigan ...................................................................... 24

Figure 4: The Second Difference of Time Series Data of Coal Consumption in

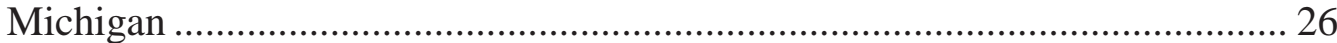

Figure 5: Sample ACF Computed on the Second Difference of Time Series Data of

Coal Consumption in Michigan ............................................................. 28

Figure 6: Sample PACF Computed on the Second Difference of Time Series Data of

Coal Consumption in Michigan ............................................................. 28

Figure 7: R output of EACF of the Second Difference of Time Series Data of Coal

Consumption in Michigan............................................................................ 29

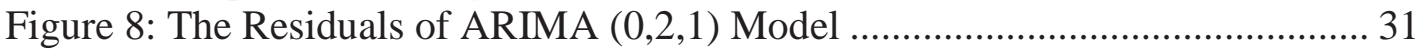

Figure 9: Q-Q Plot of the Residuals of ARIMA $(0,2,1)$ Model .............................. 32

Figure 10: Sample ACF for the Residuals of ARIMA $(0,2,1)$ Model ...................... 32

Figure 11: The Projection of Coal Consumption for Electricity Generation in

Michigan ............................................................................................ 34

Figure 12: Annual LCEs for Different Types of Technology Applied for $\mathrm{CO}_{2}$

Emission Reduction in Michigan.............................................................. 47

Figure 13: Total Cost of $\mathrm{CO}_{2}$ Emission Reduction Technologies under the $30 \%$

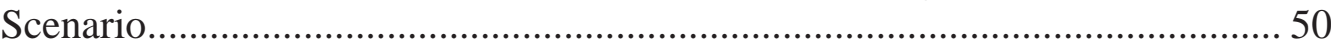

Figure 14: Total Cost of $\mathrm{CO}_{2}$ Emission Reduction Technologies under the 50\%

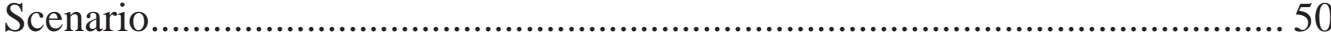

Figure 15: Annual LCEs for Different Types of Technology for $\mathrm{CO}_{2}$ Emission

Reduction in Michigan if the PTCs for Biomass Energy and Wind Power Plants

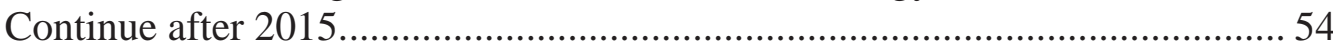

Figure 16 : Total Cost of $\mathrm{CO}_{2}$ Emission Reduction Technologies under the $30 \%$

Scenario (If PTCs for Biomass Energy and Wind Power Plants Continue after

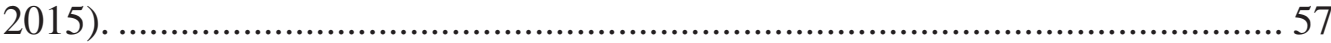

Figure 17: Total Cost of $\mathrm{CO}_{2}$ Emission Reduction Technologies under the 50\%

Scenario (If PTCs for Biomass Energy and Wind Power Plants Continue after

2015).

Figure 18: Total Cost of $\mathrm{CO}_{2}$ Emission Reduction Technologies under the $30 \%$

Scenario without PTCs for Wind and Solar Power Plants (Including the Cost of

Intermittency of Wind Power and Solar Energy).

Figure 19: Total Cost of $\mathrm{CO}_{2}$ Emission Reduction Technologies under the 50\%

Scenario without PTCs for Wind and Biomass Power Plants (Including the

Cost of Intermittency of Wind Power and Solar Energy).

Figure 20: Total Cost of $\mathrm{CO}_{2}$ Emission Reduction Technologies under the $30 \%$

Scenario (The Current PTCs for Wind and Biomass will not Change after 2015

and the Cost of Intermittency is Included) 
Figure 21: Total Cost of $\mathrm{CO}_{2}$ Emission Reduction Technologies under the 50\% Scenario (The Current PTCs for Wind and Biomass will not Change after 2015 and the Cost of Intermittency is Included)...................................................... 66

Figure A1: Residual Plot Against the Independent Variable from the Linear

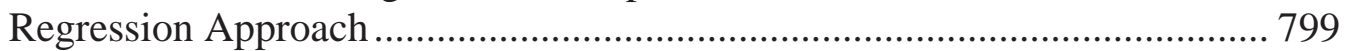

Figure A2: Q-Q Plot for the Residuals of Linear Regression Approach ................... 80 Figure A3: Sample ACF for the Standardized Residuals of the Linear Regression Model 822 


\section{List of Tables}

Table 1: The Predicted $\mathrm{CO}_{2}$ Emission from Coal-fired Power Plant under the Business as Usual Scenario........................................................................ 35

Table 2: Annual $\mathrm{CO}_{2}$ Emission Reduction Target and Actual Emission Reduction

Compared with 2005 Level.

Table 3: The Annual Additional Required $\mathrm{CO}_{2}$ Emission Reduction Compared with 2005 Level

Table 4: The Additional Amount of $\mathrm{CO}_{2}$ Emission Reductions (Billion lbs) .......... 39

Table 5: The Avoided Coal Consumption for Electricity Production (Trillions BTU)

Table 6: The Avoided Electricity Generation in the Coal Plants $\left(10^{6} \mathrm{MWh}\right)$.......... 40

Table 7: LCEs of Technologies Selected for Reducing $\mathrm{CO}_{2}$ Emission in Michigan 46

Table 8: The Total Cost of Reducing $\mathrm{CO}_{2}$ Emission by Substituting Coal by Other Energy Sources (Million \$2009).................................................................. 49

Table 9: LCEs of Technologies Selected for Reducing $\mathrm{CO}_{2}$ Emission in Michigan Assuming PTCs for Wind Power and Biomass Power Plants Continue .......... 53

Table 10: The Total Cost of Reducing $\mathrm{CO}_{2}$ Emission by Substituting Coal by Other Energy Sources if PTC for Wind Power and Biomass Power Plants Continue (Million \$2009) .......................................................................................... 56

Table 11: LCEs of Wind and Solar Power Plant Including the Cost of Intermittency

(Excluding PTCs for Wind and Biomass Power Plants) ............................... 60

Table 12: The Cost of Reducing $\mathrm{CO}_{2}$ Emission by Substituting Coal by Other Energy Sources Including the Cost of Intermittency (Excluding PTCs for Wind and Biomass Power Plants) (Million \$2009) ................................................... 61

Table 13: The Cost of Reducing $\mathrm{CO}_{2}$ Emission Technologies Including the PTCs for Wind Power and Biomass Energy Plant After 2015 (Cost of Intermittency

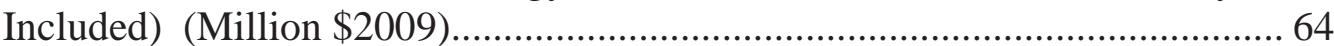

Table 14: Cost Ranges of $\mathrm{CO}_{2}$ Emission Reduction and Least-cost Strategies (2009\$)

Table A1: Coal Consumption for Electricity Generation from 1960 to 2011 in Michigan

Table A2: The R Outputs of the Predicted Values, 95\% Prediction Intervals, and Standard Errors of Prediction. 


\section{Acknowledgements}

It is impossible to finish this master's thesis without the help and support from the kind people around me. I would like to express my deep gratitude to several individuals who have helped me to make this possible. Above all, I would like to thank my mother, Liying $\mathrm{Bi}$, and my father, Baoquan $\mathrm{Li}$, for encouraging and supporting me to finish my second master's degree.

Next, I want to show my sincerest respect to my supervisor, Dr. Mark C. Roberts, for his continuous help and support in my three year's study in Michigan Technological University. This thesis would not have been completed without his instruction, patience, and encouragement.

Besides my advisor, I want to thank my other thesis committee members: Dr. Garry A. Campbell and Dr. Min Wang, for their additional instructions, and for their critical and insightful comments throughout this thesis.

Last but not least, I want to thank my friend Yan $\mathrm{Yu}$, who helped me scan the commented drafts and emailed them to me during my internship in UN ESCAP. Any error that may remain in this work is entirely my own responsibility. 


\section{List of Abbreviations}

ACF Autocorrelation Function

AEO Annual Energy Outlook

AIC Akaike's Information Criterion

AR Autoregressive

ARIMA Autoregressive Integrated Moving Average

BAU Business-as-usual

BIC Bayesian Information Criterion

BJ Box-Jenkins

BTU British Thermal Unit

CCS $\mathrm{CO}_{2}$ Capture and Storage

$\mathrm{CO}_{2}$ Carbon Dioxide

EACF Extended Autocorrelation Function

EIA U.S. Energy Information Administration

EOP Executive Office of the President

EPA U.S. Environmental Protection Agency

GDP Gross Domestic Product

GHG Greenhouse Gas

I Integration

IPCC Intergovernmental Panel on Climate Change

ITC Investment Tax Credit

kWh Killiowatt Hour

lb Pound 
LCE Levelized Cost of Energy

LOS Least of Square

MA Moving Average

MWh Megawatt Hour

PACF Partial Autocorrelation Function

PTC Production Tax Credit

R\&D Research and Development

RPS Renewable Portfolio Standard 


\begin{abstract}
This thesis attempts to find the least-cost strategy to reduce $\mathrm{CO}_{2}$ emission by replacing coal by other energy sources for electricity generation in the context of the proposed EPA's regulation on $\mathrm{CO}_{2}$ emissions from existing coal-fired power plants. An ARIMA model is built to forecast coal consumption for electricity generation and its $\mathrm{CO}_{2}$ emissions in Michigan from 2016 to $2020 . \mathrm{CO}_{2}$ emission reduction costs are calculated under three emission reduction scenarios- reduction to $17 \%, 30 \%$ and $50 \%$ below the 2005 emission level. The impacts of Production Tax Credit (PTC) and the intermittency of renewable energy are also discussed. The results indicate that in most cases natural gas will be the best alternative to coal for electricity generation to realize $\mathrm{CO}_{2}$ reduction goals; if the PTC for wind power will continue after 2015, a natural gas and wind combination approach could be the best strategy based on the least-cost criterion.
\end{abstract}




\section{Chapter: 1 Introduction}

\subsection{Background}

According to the Intergovernmental Panel on Climate Change (IPCC 2013), the increase in atmospheric concentrations of carbon dioxide $\left(\mathrm{CO}_{2}\right)$ and other greenhouse gases (GHGs) has resulted from human activity since 1750. The scientists also declare that it is extremely likely that the observed warming since 1950 is mainly influenced by human activities (IPCC 2013). Global warming causes changes in water cycles, sea level rise, climate extremes, etc. (IPCC 2007; IPCC 2013). To reduce the negative impacts from global warming, it is necessary to control the emissions of $\mathrm{CO}_{2}$ and other GHGs from human activities.

In 2009, President Obama pledge to reduce American GHGs emission by $17 \%$ below 2005 emission level by 2020. To achieve this goal, the Obama Administration wants to double electricity generation from renewable energy resources and update new fuel economy standards (EOP 2013). The total amount of GHGs emission in 2005 and 2011 are 7,195 and 6,702 million metric tons ( $\mathrm{CO}_{2}$ equivalent), respectively (EPA 2013). The total GHG emissions in 2011 decreases by 6.9 percent below the 2005 emission level. However, it is uncertain that whether or not Obama's 17\% Goal will be achieved by 2020. According to U.S. Environmental Protection Agency (EPA)'s Inventory of U.S. Greenhouse Gases and Sinks, in 2011, 33\% of GHGs was emitted from electricity production, which was the single largest GHGs emissions source in the U.S. (EPA 2013). Also, about $67 \%$ of the electricity was generated from coal and natural gas in $2011^{1}$.

\footnotetext{
${ }^{1}$ See Table 1.1 on http://www.eia.gov/electricity/annual/, retrieved on Jan $10^{\text {th }}, 2014$.
} 
To reduce the carbon pollution from the electric industry, in September 2013 the EPA proposed carbon dioxide emission standards for coal-fired and natural gas power plants which will be built in the future ${ }^{2}$. This was EPA's first strong action under President Obama's Climate Action Plan. However, these strict standards only regulate new coal-fired and natural gas power plants. The program to reduce carbon emission from existing power plants is still under consideration ${ }^{3}$.

However, existing power plants emit large quantities of GHGs. According to the EIA, electricity in the U.S. declined in the four of years from 2008 to 2012; and it continued to decline continuingly in $2013^{4}$. It is possible that, with the current trend, there would be no need to expand the current electricity generation capacity. Thus, in the electric industry, the major contributor of carbon emission is still the existing power plants. If the Obama Administration wants to achieve the ambitious goals of the Climate Change Plan, the regulation to reduce carbon emission from existing power plants needs to be worked out.

Michigan depends heavily on fossil fuels to generate electricity. For example, in 2010 the primary resource for electricity generation is coal, which accounted for $58.81 \%$ of total electricity generation ${ }^{5}$. A large amount of $\mathrm{CO}_{2}$ is emitted from the Michigan electric power sector. According to the U.S. Energy Information Administration (EIA), in

\footnotetext{
${ }^{2}$ More details about the proposed separate standards for new coal and natural gas based power plants can be found at http://www.gpo.gov/fdsys/pkg/FR-2014-01-08/pdf/201328668.pdf , retrieved on April 11th, 2014.

${ }^{3}$ See http://www2.epa.gov/sites/production/files/201309/documents/20130923statequestions.pdf, retrieved on Jan 11 ${ }^{\text {th }}, 2014$.

${ }^{4}$ See http://www.eia.gov/todayinenergy/detail.cfm?id=14291, retrieved on Jan $11^{\text {th }}, 2014$.

${ }^{5}$ See Table 5 on http://www.eia.gov/electricity/state/michigan/, retrieved on Jan $8^{\text {th }}, 2014$.
} 
2010, Michigan's total amount of $\mathrm{CO}_{2}$ emissions from electricity generation was 74, 480 thousand metric tons, which ranked $11^{\text {th }}$ among all the states in the U.S $S^{5}$. Thus, reducing the carbon emission from the existing power plants will be a great challenge to Michigan.

\subsection{Study Purpose and Thesis Structure}

Various technologies are available to avoid carbon emissions in the electric power sector, such as $\mathrm{CO}_{2}$ capture and storage (CCS), improving energy efficiency and replacing fossil fuels by low or non-emission energy resources. The ultimate goal of this thesis is to estimate the cost of reducing $\mathrm{CO}_{2}$ emission by different technologies in the Michigan electric power industry under different $\mathrm{CO}_{2}$ emission reduction targets. Also, by comparing the costs of available low-carbon technologies, this thesis attempts to help Michigan electricity providers to find the most cost-effective strategy to avoid releasing $\mathrm{CO}_{2}$ from electricity production.

Coal is the primary energy resource to generate electricity, and nearly $90 \%$ of total $\mathrm{CO}_{2}$ in the Michigan electric power industry is emitted from coal-fired power plants ${ }^{6}$. Therefore, this thesis only estimates the cost of $\mathrm{CO}_{2}$ emission reduction strategies for existing coal-fired power plants.

The rest of this thesis is organized as follows: the literature review and the methodologies for analysis are presented in Chapter 2. Chapter 3 mainly focuses on building statistical models to project future $\mathrm{CO}_{2}$ emissions in Michigan coal-fired power

${ }^{6}$ See Table 7 on http://www.eia.gov/electricity/state/michigan/, retrieved on Feb $4^{\text {th }}$, 2014. 
plants. Based on the results in Chapter 3, Chapter 4 will conduct cost analysis of $\mathrm{CO}_{2}$ emission reductions. At the end of this chapter, the cost ranges and least cost strategies under different emission reduction scenarios will be provided. Some uncertain factors, like the intermittency feature of renewable energy and the production tax credit for renewable power plants, may influence the results of the cost analysis. In Chapter 6, the impacts of these factors will be discussed. The conclusions and limitations of this thesis, and the implications for future studies will be presented in Chapter 7. 


\section{Chapter 2: Literature Review and Methodology}

Most current studies focus on estimating the $\mathrm{CO}_{2}$ mitigation cost for a global or a national level. For example, Sim et al. (2003) compares the mitigation costs of technologies, which can contribute to reducing carbon emission from electricity generation. They found that except for solar energy power plants and carbon dioxide sequestration technologies, other carbon emission-reducing technologies (like nuclear and other renewable energy power plants) have the potential to reduce both the cost of electricity generation and carbon emissions by 2020 from a global level.

Crane et al. (2011) estimate the cost of a national 25 percent Renewable Portfolio Standard (RPS) in the U.S. by 2025. In their study, it is assumed that a $25 \%$ RPS only replaces coal by renewable energy resources to generate electricity. A national $25 \%$ RPS can reduce about 670 million metric tons of GHG emissions per year. However, this study only discusses the role of renewable energy resources to reduce carbon emissions from coal-fired power plants.

Fischer and Newell (2007) assess the $\mathrm{CO}_{2}$ emission reduction polices and the ones aimed at renewable energy technology diffusion and innovation. It is found that emission price is the most effective single carbon emission reduction policy. It works well except for small emissions reduction targets. Also, a portfolio of policies, rather than one single policy, can lower the cost considerably, especially if emissions price and R\&D and learning subsidies are included. 
Few studies have analyzed the issue from a state level. Also, there remains a need to incorporate all the alternative energy sources (renewable energy, nuclear energy, lowcarbon emission fossil fuels) into consideration, and compare their individual behaviors and costs of carbon emission reductions.

The methodology of this thesis is presented as follows: First, the thesis projects the future $\mathrm{CO}_{2}$ emissions from coal-fired plants in Michigan. A time series model based on Box-Jenkins (BJ) methodology can be built to predict coal demand for electricity generation. Then, future $\mathrm{CO}_{2}$ emissions can be estimated by multiplying the annual coal consumption by the $\mathrm{CO}_{2}$ emission factor ${ }^{7}$.

Next, the $\mathrm{CO}_{2}$ reduction targets will be determined. Reduction to $17 \%$ below 2005 $\mathrm{CO}_{2}$ emission level by 2020 (proposed by the Obama Administration) is regarded as one scenario. Also, a progressive target- reduction to 30\% below 2005 level by 2020, and an even more challenging target-reduction to $50 \%$ below 2005 level by 2020 - are used to estimate the potential cost under more stringent regulations.

Based on the annual emission reduction target, which is decomposed from the ultimate target of the different scenarios, the required avoided electricity generation from coal and avoided coal consumption for electricity generation can be calculated. The cost can be approximated by multiplying the avoided electricity generation from coal by the electricity generation cost of the alternative energy resource. One can find the cost of electricity produced from different energy sources from other studies, governmental and

\footnotetext{
${ }^{7}$ See http://www.eia.gov/tools/faqs/faq.cfm?id=74\&t=11
} 
industry reports. In this thesis, the information is gathered from EIA's Levelized Cost of Energy in the Annual Energy Outlook (AEO) (EIA 2011b, 2012b, 2013b, 2014b).

Finally, the total cost of all the alternative technologies proposed to reduce $\mathrm{CO}_{2}$ emission for coal-fire power plants can be estimated and compared. The least cost one will be recommended as the most promising energy resource to replace coal to generate electricity under the $\mathrm{CO}_{2}$ emission reduction requirement. 


\section{Chapter 3: Projecting Future $\mathrm{CO}_{2}$ Emission from Coal-Fired Power Plants in Michigan}

Before estimating the cost of replacing coal by other energy sources, the $\mathrm{CO}_{2}$ emission reduction target should be determined. In other words, the cost estimation for each alternative energy technology in this study is mainly based on how much $\mathrm{CO}_{2}$ emissions should be avoided. Thus, it is necessary to estimate the total $\mathrm{CO}_{2}$ emitted from the existing coal-fired power plants in Michigan currently. The rest of this chapter will discuss how to build a time series model to project future $\mathrm{CO}_{2}$ emissions.

\subsection{Literature Reviews of Forecast Models}

Many methods are available for forecasting electricity demand. For example, Mohamed and Bodger (2005) built a multiple linear regression model to forecast the electricity consumption in New Zealand. They found that gross domestic product (GDP), the average price of electricity and the population of New Zealand are highly related to New Zealand's electricity demand. A simulation approach based on artificial neural network can be used to forecast monthly electricity consumption (Azadesh et al. 2008). Also, some scholars applied the Grey Prediction method to forecast electricity demand (Yao et al. 2003; Zhou et al. 2006).

Another popular approach is building an Autoregressive Integrated Moving Average (ARIMA) models to project electricity demand (Hagan and Behr 1987; Abdel-Aal and Al-Garni 1997; Pappas et al. 2008). The ARIMA (p,d,q) model includes three parts: the autoregressive (AR), integration (I) and moving average (MA) terms. In the AR ( $p)$ and 
MA $(q)$ model, the dependent variable is linearly regressed on its own previous values and its past forecast errors, respectively. Both $p$ and $q$ indicate the time lag in the model or the order of model. I $(d)$ serves as the integration part of the model. The time series data becomes stationary after differencing $d$ times.

Here are the reasons why this thesis uses ARIMA model for forecasting rather than other approaches. First, the forecast of ARIMA model is only based on analyzing the historical data. It is assumed that the past data includes the influences of all the possible explanatory variables and the pattern of those influences will continue in the future. To build an ARIMA model, there is no need to find the exact influential factors and analyze their impacts on the dependent variable like multiple linear regression approach. Second, the model applied in this thesis only needs forecasting the data a few years ahead and ARIMA models do well in this case. However, the long-term predictions of ARIMA model can have very wide prediction intervals. Last but not the least, the ARIMA model has the advantage of responding quickly to changes in underlying trends. Thus, the ARIMA model is selected as the forecasting model in this thesis. The methodology of establishing ARIMA models for time series analysis in this study is mainly based on the Box and Jenkins (2013) study. With the help of the R statistical software package, one can build ARIMA models for projection. In this study, most of the $\mathrm{R}$ codes for analyzing the time series data, building the appropriate ARIMA model and predicting the future trend is based on the study by Cryer and Chan (2008).

The goal of this section focuses on forecasting annual $\mathrm{CO}_{2}$ emissions. However, in this study the ARIMA model based on Box-Jenkins (B-J) methodology is only applied to 
the time series data of coal consumption, rather than $\mathrm{CO}_{2}$ emission, to project future coal demand for electricity generation in Michigan. Ultimately, one can estimate the annual quantity of $\mathrm{CO}_{2}$ emission by multiplying the total coal consumption for electricity generation by $\mathrm{CO}_{2}$ emission per unit of coal used in power plants. There are 3 major steps to find an appropriate ARIMA models for precise prediction: model identification, parameter estimation, and model diagnosis. Based on these steps, the rest of this chapter will present how to find an appropriate ARIMA model to forecast future coal use for electricity generation and thus $\mathrm{CO}_{2}$ emission from coal-fired power plants in Michigan.

\subsection{Building the ARIMA Model}

\subsubsection{Model Identification}

Michigan's annual coal consumption for electricity generation from 1960 to 2011 is available from EIA's State Profile and Energy Estimates website ${ }^{8}$. First, one can plot the data of annual coal consumption for electricity generation against time to check the trend of the data. Figure 1 shows the results of the plot. The original data are presented in Appendix A of this thesis. Based on the plot of the raw data, the coal consumption for electricity generation is apparently decreasing after 2007 in Michigan.

\section{Linear Approach}

If a simple model can summarize all the information in the data, there is no need to build a complex one. Thus, before applying an ARIMA model to fit the data, one simple liner regression model is checked to see if it fits the data well or not. According to Figure

\footnotetext{
${ }^{8}$ Seehttp://www.eia.gov/state/seds/data.cfm?incfile=/state/seds/sep_use/eu/use_eu_MI.html\&sid=MI, retrieved on March 16, 2014.
} 


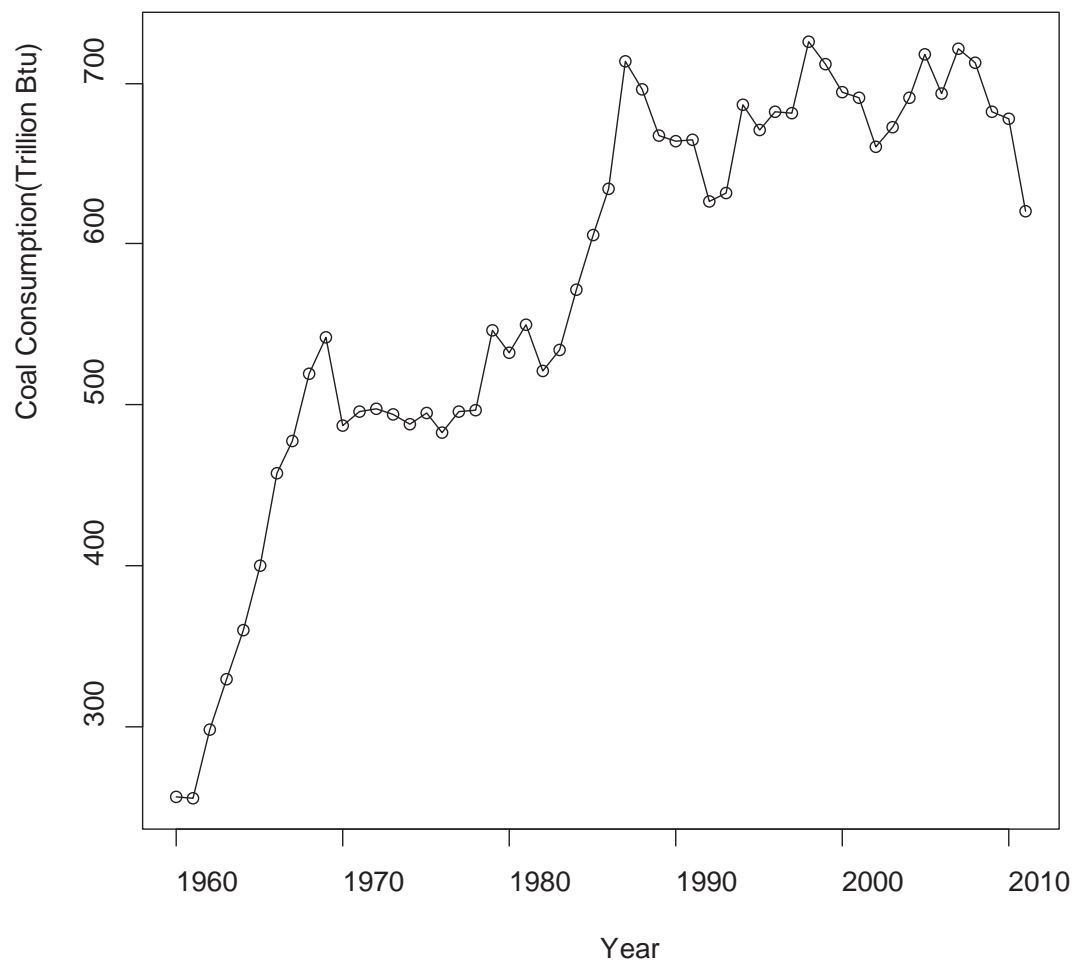

Figure 1: Coal consumption for electricity generation from 1960 to 2011 in Michigan.

1 , it is not easy to find a perfect function to describe the relationship between the annual coal consumption and year. Thus, a linear regression model is built by using coal consumption $(\mathrm{C})$ as the dependent variable and Year (t) as the independent variable. The regression results from $\mathrm{R}$ are shown in the Appendix B of the thesis.

Based on the results, one can conclude that at a $95 \%$ confidence level, the coefficient of Year ( $\mathrm{t}$ ) is statistically significant from the t-test. The Multiple R-squared indicate the model can explain the $80.21 \%$ of the data by using Least of Square (LOS) method. Also, the whole model is significant based on the F-statistic. 
However, when plotting the residuals against the independent variable, the residuals are not evenly distributed on both sides of the zero line, and a possible increasing trend exists (See Appendix C). Also, one can check the normality of the residuals by Q-Q plot. A Q-Q plot is a plot of the percentiles of distributions of the observed data against the percentiles of a standard normal distribution. If the observed data are close to a normal distribution, the plot looks like a straight line. For a good fitting model, it is assumed that the residuals follow a normal distribution if the model is a proper to fit the data. However, based on the Q-Q plot shown in Appendix D, the distribution of the residuals is not a straight line, which means that it contradicts the assumption of normality of the residuals.

Also, it is assumed that the residuals are independent and have no correlations. The Durbin-Watson test can be is applied to check whether or not the residuals are correlated (Durbin and Watson 1971). The results of the Durbin-Watson test are shown in Appendix E. At a 95\% significance level, from lag 5, we cannot reject the null hypothesis that autocorrelation of the residuals is 0 , which means the residuals before lag 5 are highly correlated. Also the sample autocorrelation function (ACF) for the standardized residuals in Appendix F provides similar conclusion: before lag 4, the residuals are highly related. Based on the above findings, the linear regression model cannot be applied to fit the data. As this statistical work confirms, Figure 1 is not a linear plot.

\section{ARIMA Approach}

The ARIMA model should be built from stationary time series data with constant mean and variances. The first step of model identification is checking whether or not 


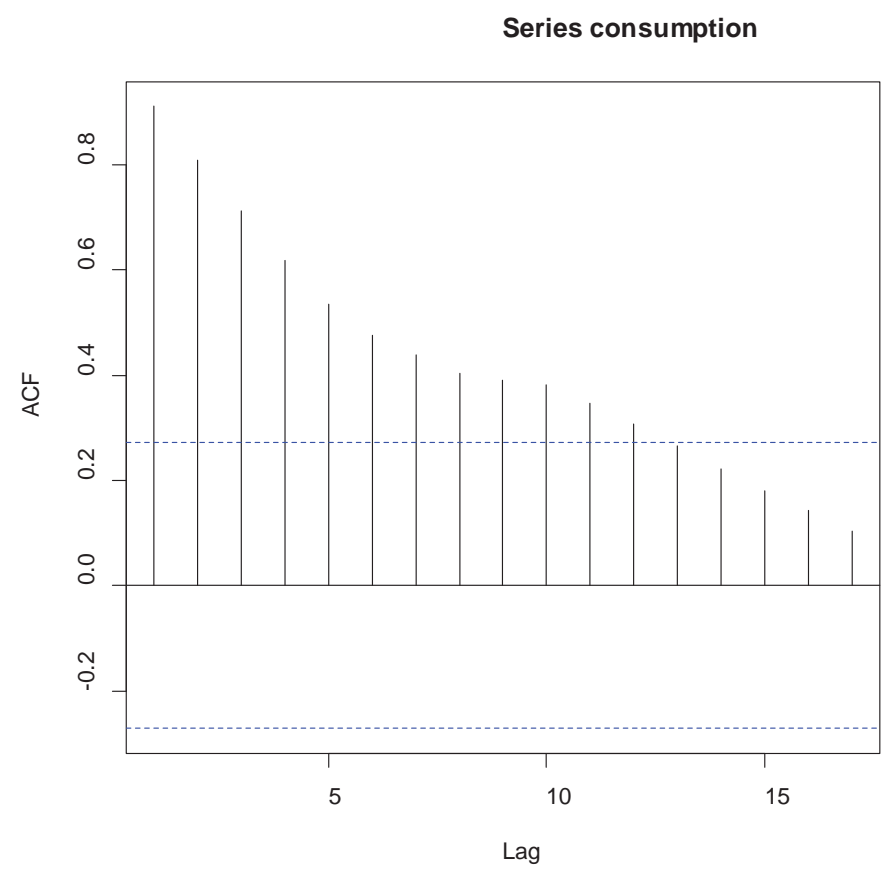

Figure 2: Sample ACF for Time Series Data of Coal Consumption in Michigan

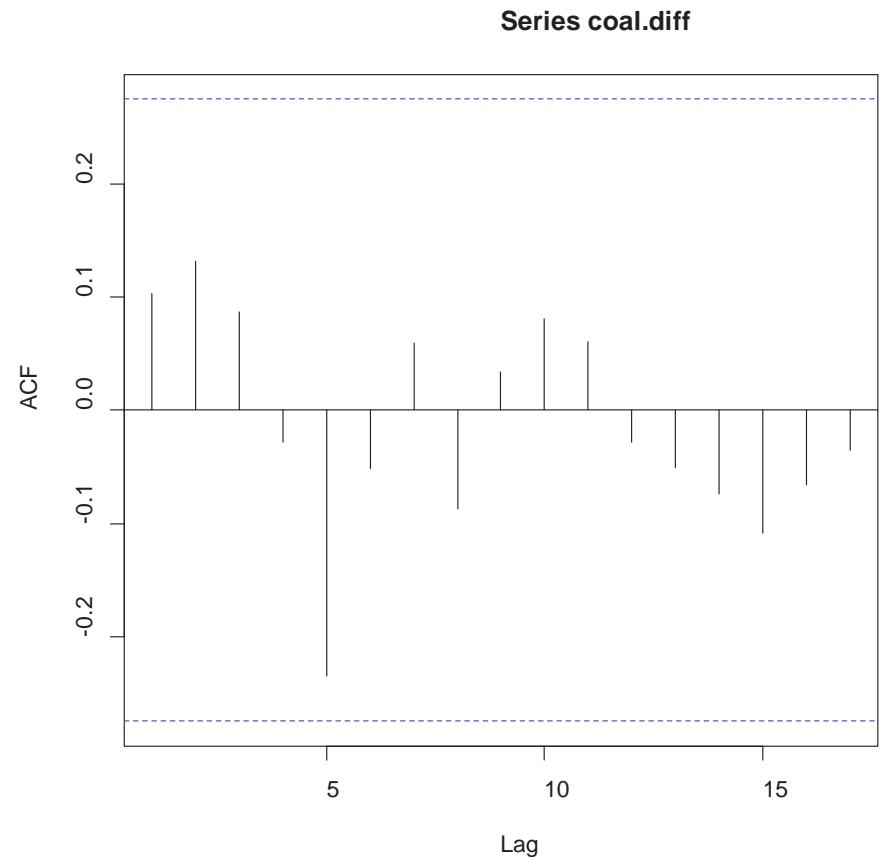

Figure 3: Sample ACF Computed on the First Difference of Time Series Data of Coal Consumption in Michigan 
transformation is needed to make the time series data stationary. Differencing can remove the non-stationarity of the data. The purpose of differencing is to attain a more homogeneous mean and more stable variance. The order of differencing can be determined by checking the ACF of the time series data. Figure 2 shows the results of computing the sample ACF for the raw data. Apparently, there is a decreasing trend in the sample ACF of the data. The sample ACF drifts slowly and does not disappear rapidly when the lag is increasing. Thus, the data needs differencing. Figure 3 presents the sample ACF of the differencing data. Obviously, after the differencing, the slowly decreasing trend of the sample ACF disappears, and it seems that no certain trend exists.

The Dickey Fuller Unit Root test can be applied to test whether or not the first difference of the original time series data is stationary (David and Fuller 1979). The null hypothesis of the test is that a unit root exists, which means that the time series data is not stationary. The alternative hypothesis is that there is no unit root. The results of the test are shown in Appendix G. In this case, the p-value is greater than $\alpha$ of $0.05(5 \%)$, thus we cannot reject the null hypothesis of a unit root. Thus, the first difference of the data is still not stationary, and further differencing may be needed. Appendix $\mathrm{H}$ shows the results of the Dickey Fuller Unit Root test for the second difference of the data. Since the p-value is less than 5\%, we can reject the null hypothesis and conclude that the data after the second differencing is now stationary.

Figure 4 shows the second difference of the original data. The new series of data looks evenly distributed around the zero line, and no specific pattern or trend exists 


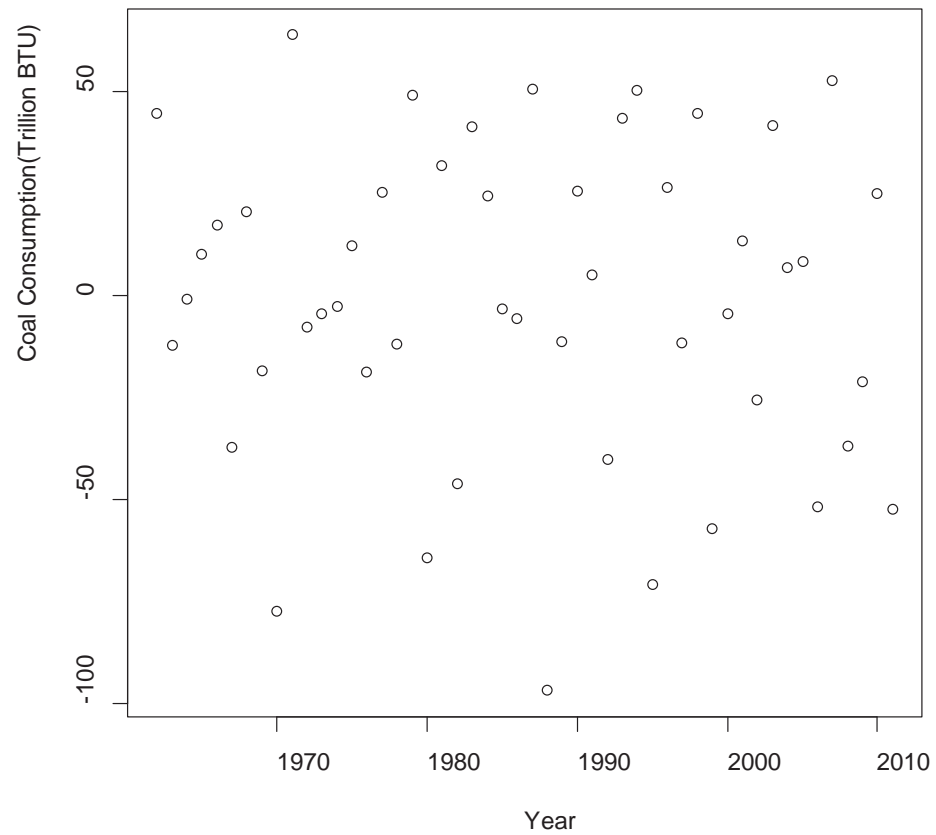

Figure 4: The Second Difference of Time Series Data of Coal Consumption in Michigan

comparing with the plot of original data in Figure 1. Here, it should be mentioned that after differencing twice, two observations are lost in Figure 4.

However, one should be cautious about the disadvantages of differencing. First, differencing causes the loss of one observation each time. Also, overdifferencing can introduce unnecessary correlations into a series and make the modeling process more complicated (Cryer and Chan 2008). To check whether or not the second difference of the data causes unexpected correlations of the time series data, one can calculate the ACF of the second differences. The results are shown in Figure 5. Compared with Figure 3, which shows the sample ACF for the first difference of data, lag 1 has a strong correlation and the correlation at lag 5 is significant. However, usually, at most two 
differences and some transformations can stabilize the data (Cryer and Chan 2008). Thus, differencing the data twice is accepted in this study in spite of the unexpected correlations introduced by differencing the data.

The next step is specifying the model. The model identification procedures are mainly due to Cryer and Chan (2008). In this study, the ARIMA model is selected based on the ACF, partial (PACF) and extended ACF (EACF). According to Figure 5, which represents the ACF of the second difference of data, the ACF cuts off at lag 1. The dashed lines in Figure 5 shows the critical values for checking whether the coefficients of the ACF are significantly different from zero or not. The behavior of ACF indicates that the MA (1) model is appropriate to fit the data. The PACF of the second difference of the data is shown in Figure 6. The PACF cuts off at lag 2, which means that AR (2) should be considered. To further check which ARIMA model is appropriate to fit the data, EACF will be applied next. The R outputs of EACF are shown in Figure 7.

The first appearance of zero can indicate the orders of AR and MA terms of the ARIMA model. The above EACF results supports the previous assumption that MA (1) model is worthy of consideration. However, there is uncertainty about whether or not the model should incorporate the autoregressive part, ARMA $(2,1)$, which is based on the ACF and PACF of the differenced data. It is tested to check how well it fits the data. Finally, the two possible models ARIMA $(0,2,1)$ and ARIMA $(2,2,1)$ are selected when considering the second difference of data. 


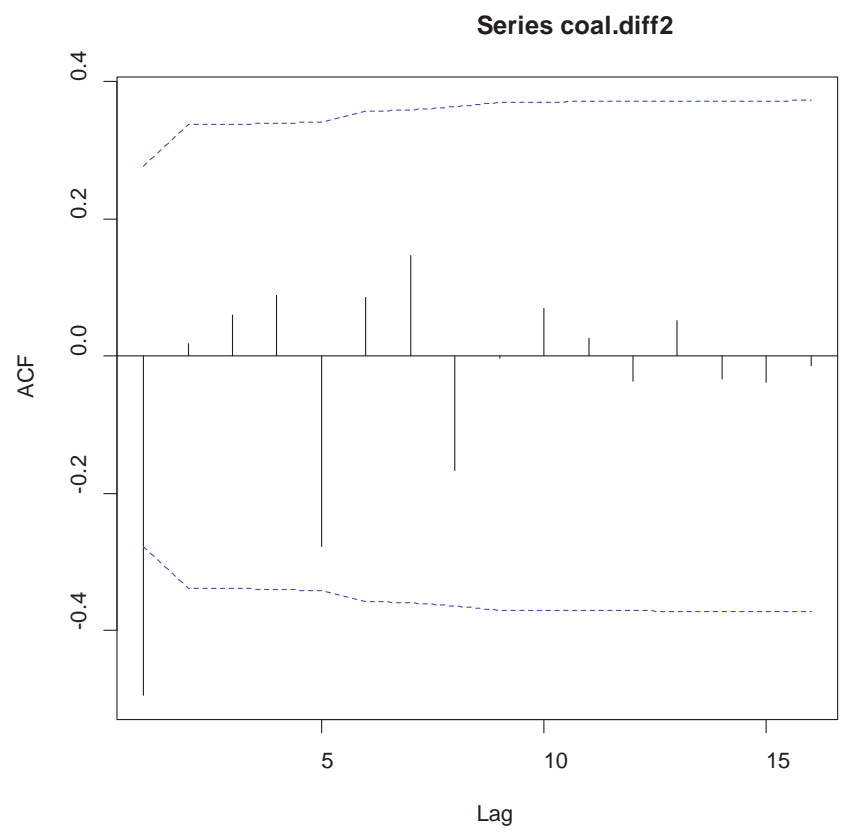

Figure 5: Sample ACF Computed on the Second Difference of Time Series Data of Coal Consumption in Michigan

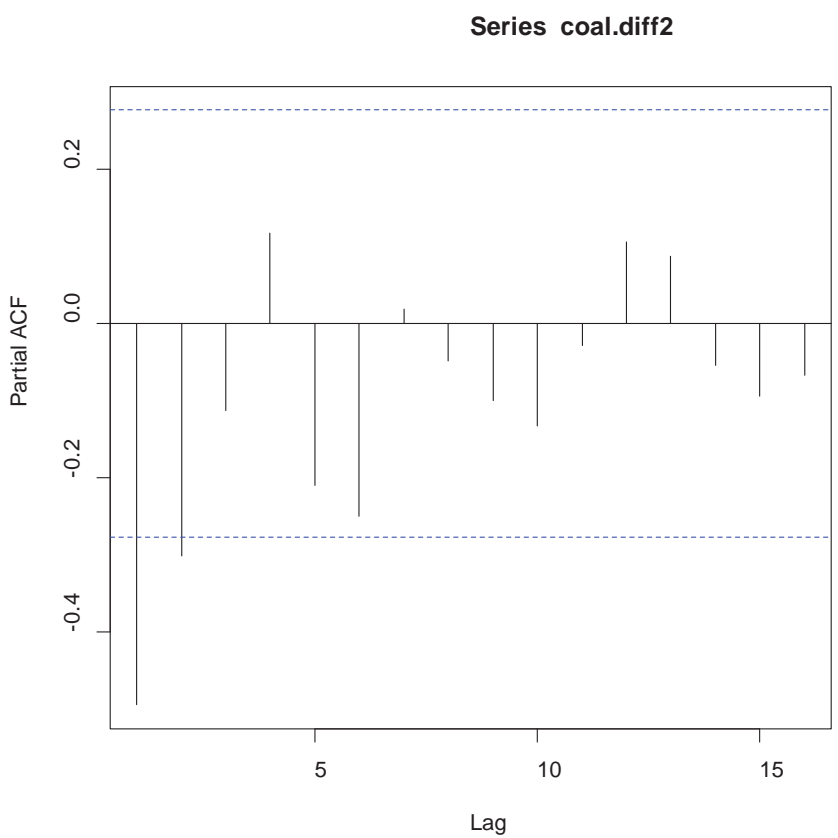

Figure 6: Sample PACF Computed on the Second Difference of Time Series Data of Coal Consumption in Michigan 


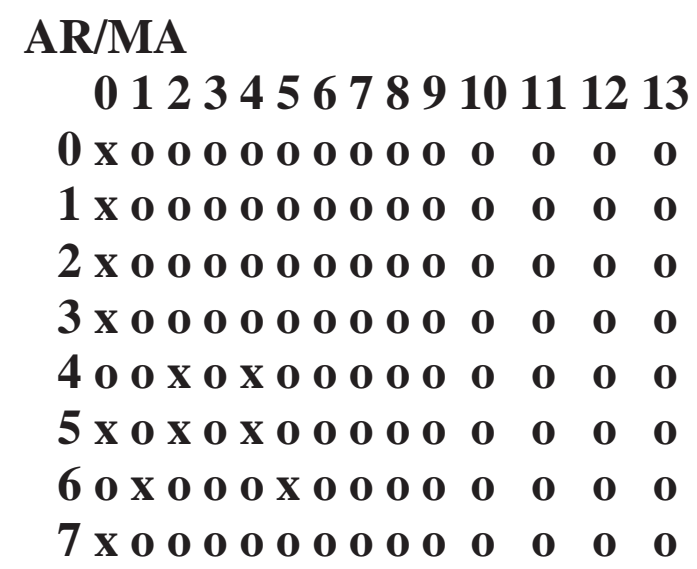

Figure 7: R output of EACF of the Second Difference of Time Series Data of Coal Consumption in Michigan

Normally, the following step is used to answer the question: which model is more appropriate and can be adopted for predicting future coal consumption for electricity generation in Michigan. Akaike's Information Criterion (AIC), Bayesian Information Criterion (BIC) and residual analysis will be tested for final model selection. The $\mathrm{R}$ software provides the results of AIC, BIC and the parameter estimates. The model selection will be discussed together with parameter estimation in the next section.

\subsubsection{Parameter Estimation and Model selection}

Box et al. (2013) discuss how to select the optimal model by using AIC and BIC, and how to estimate the parameters of an ARIMA model by maximizing the likelihood function. The maximum likelihood method uses all the information in the data and it can generate "many large-sample results which are known under very general conditions" (Cryer and Chan 2008). The R parameter estimates of the ARIMA $(2,2,1)$ and ARIMA 
$(0,2,1)$ models by using maximum likelihood method, and AIC and BIC for each model are shown in Appendix I and Appendix J, respectively. Among all the candidate models for the same data set, the promising model should have the minimum AIC and BIC values. In other words, the lower the values of AIC and BIC are, the better the model fits the data. Comparing the fitting results of two candidate models, ARIMA $(0,2,1)$ has the lower AIC, and BIC values. Thus, it is regarded as the better model.

The "forecast" package in R has an auto.arima function, which can help to inspect the best the ARIMA (p,d,q) model based on AIC and BIC criterion. By default, this function limits the value of $\mathrm{p}$ and $\mathrm{q}$ from 0 to 5. According to the results, which are present in Appendix K, the most appropriate model is ARIMA $(0,2,1)$. This confirms that the reasoning processes in the previous section to find the best model are correct.

Although the auto.arima function does not consider the intercept of the model, this does not impact the results of finding the most appropriate ARIMA model the data. However, it is too early to conclude that $\operatorname{ARIMA}(0,2,1)$ is the ultimate model before a residual analysis is done. Residual analysis is an important model diagnostics method which is necessary to further check the goodness of the model.

\subsubsection{Model Diagnosis}

A diagnosis check is mainly conducted on the residuals. Residuals should follow a white noise process, which means it must fulfill the following requirements: normal distribution, zero mean, constant variance, and the residuals are uncorrelated to each other. 


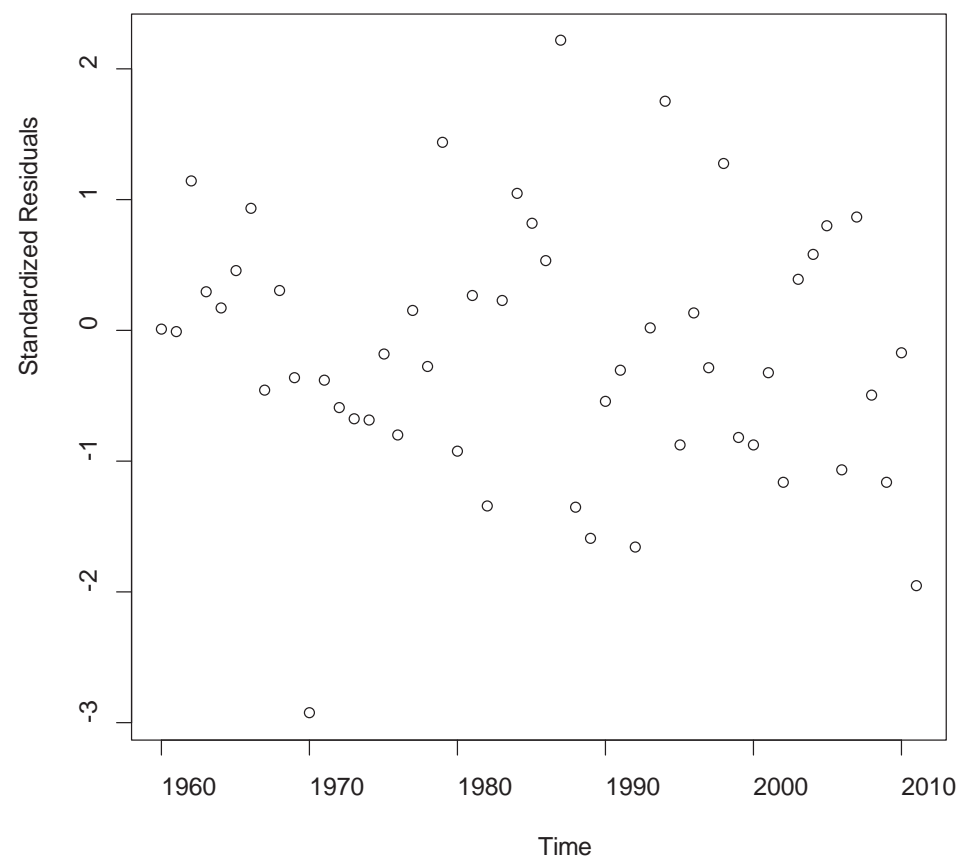

\section{Figure 8: The Residuals of ARIMA $(0,2,1)$ Model}

First, the residuals of the model are plotted over time to check whether or not the results have any pattern. Figure 8 shows the residuals from the ARIMA $(0,2,1)$ model of coal consumption. The plot suggests most of the residuals randomly scatter around a zero and weak heteroskedasticity exists.

Next, the normality of residuals will be checked. It is assumed that the residuals follow a normal distribution. The Q-Q plot is shown in Figure 9. Most of the residuals seem to be on a straight line except in the extreme tails. Although several points are wondering off around the upper right tail of the plot, overall, we can concluded that residuals are normally distributed.

The last but not the least step is to examine whether or not the residuals are correlated. It is expected that the residuals are not correlated to each other. Figure 10 


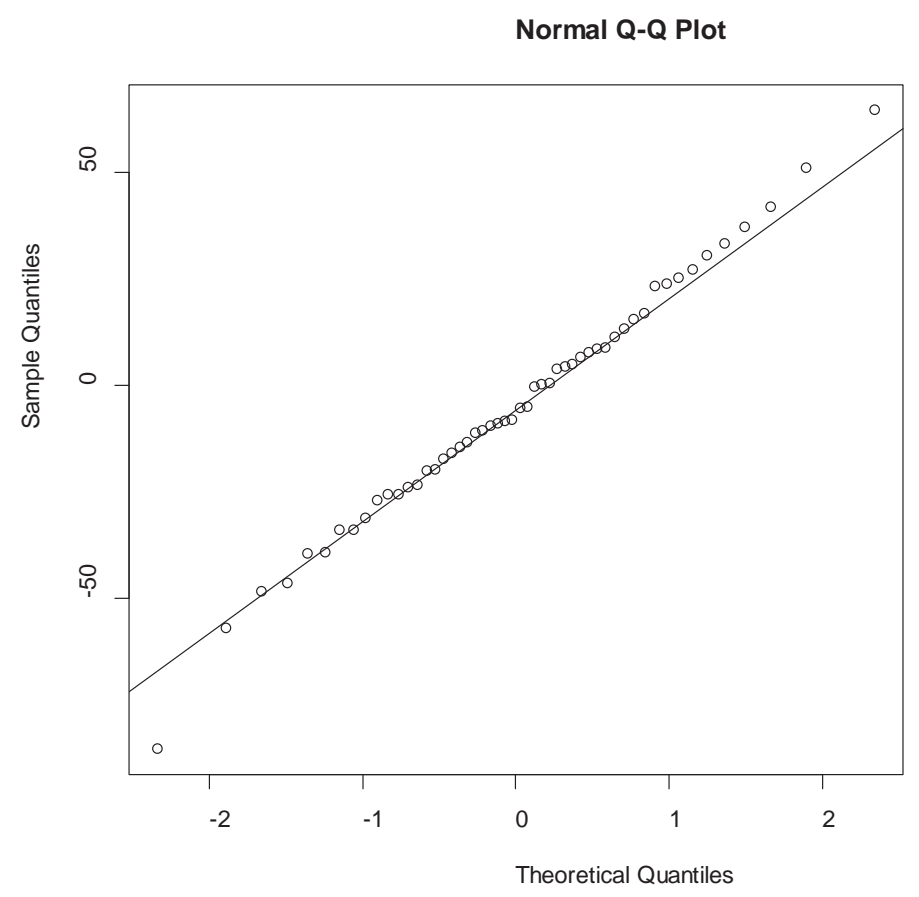

Figure 9: Q-Q Plot of the Residuals of ARIMA $(0,2,1)$ Model

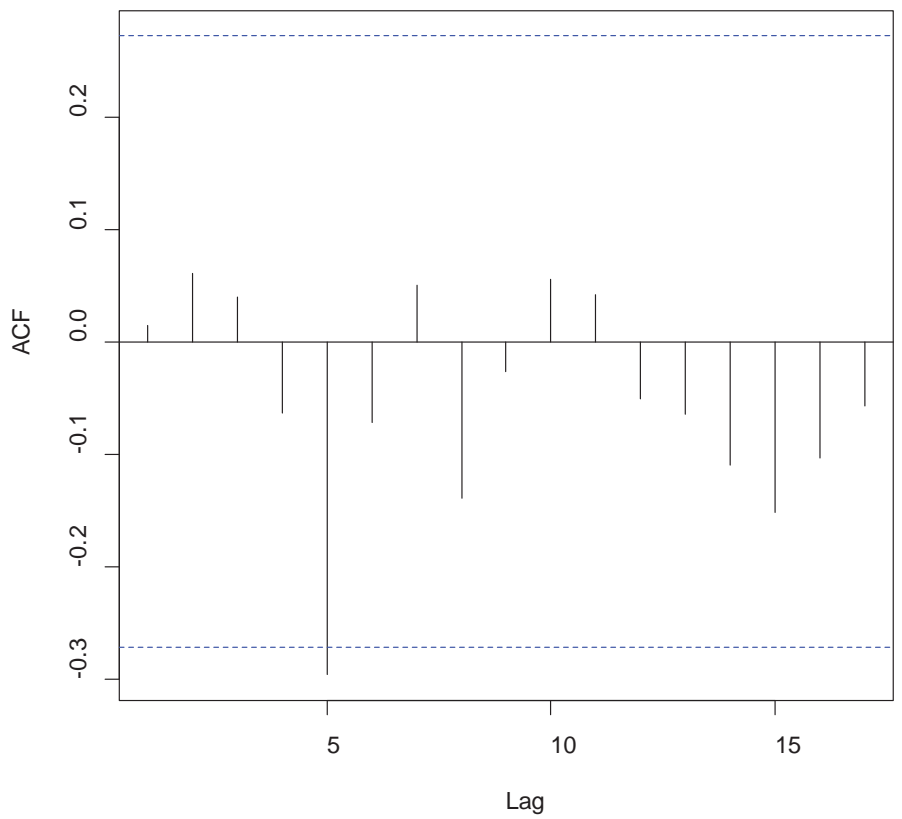

Figure 10: Sample ACF for the Residuals of ARIMA $(0,2,1)$ Model 
presents the ACF of residuals. It is obvious that only at lag 5 is there a slightly significant autocorrelation. However, considering no strong autocorrelations exist at other lags, one can still conclude that there is no statistically powerful autocorrelation in the residuals.

The last but not the least step is to examine whether or not the residuals are correlated. It is expected that the residuals are not correlated to each other. Figure 10 presents the ACF of residuals. It is obvious that only at lag 5 is there a slightly significant autocorrelation. However, considering no strong autocorrelations exist at other lags, one can still conclude that there is no statistically powerful autocorrelation in the residuals.

Also, the Ljung-Box test can be used to check whether or not the residuals are autocorrelated when considering their group magnitude instead of individual lags (Ljung and Box 1978). The null hypothesis is that the residuals are uncorrelated. The results of test are shown in Appendix L. At a 95\% significance level, one cannot reject the null hypothesis: thus considering all the residuals as a group, the residuals are uncorrelated.

Thus, the final model ARIMA $(0,2,1)$ is defined as :

$$
\nabla^{2} \mathbf{Y}_{t}=\theta_{0}+\mathbf{e}_{t}-\theta_{1} \mathbf{e}_{t-1}
$$

where $\nabla^{2} Y_{t}=\left(Y_{t}-Y_{t-1}\right)-\left(Y_{t-1}-Y_{t-2}\right)$

Based on the R outputs in Appendix $\mathbf{J}, \theta_{0}=18.2447, \theta_{1}=0.8906$. Thus, the model can be written as follows:

$$
\nabla^{2} Y_{t}=18.2447+e_{t}-0.8906 e_{t-1}(1)
$$

Ultimately, model (1) is appropriate to fit the data and can be applied to make a prediction of the future coal consumption for electricity generation in Michigan. 


\subsection{Projecting Future $\mathrm{CO}_{2}$ Emissions from Coal-fired Power Plant in Michigan}

Model (1) is now used to predict the future coal consumption needed for electricity generation in Michigan from 2012 to 2020. The results are shown in Figure 11. In Figure 11, the solid circles represent the predicted values from 2012 to 2020. The predicted values describe a continuously decreasing trend in coal consumption after 2007. The upper and lower dashed lines around the predicted values are the 95\% prediction bounds. The output of the predicted values, $95 \%$ prediction intervals, and standard errors of prediction are shown in Appendix M. One limitation of the prediction is that the standard errors, lower and upper predicted intervals for the years after 2012 become greater and greater. Other limitations of applying an ARIMA model for forecasting will be discussed in Chapter 6 .

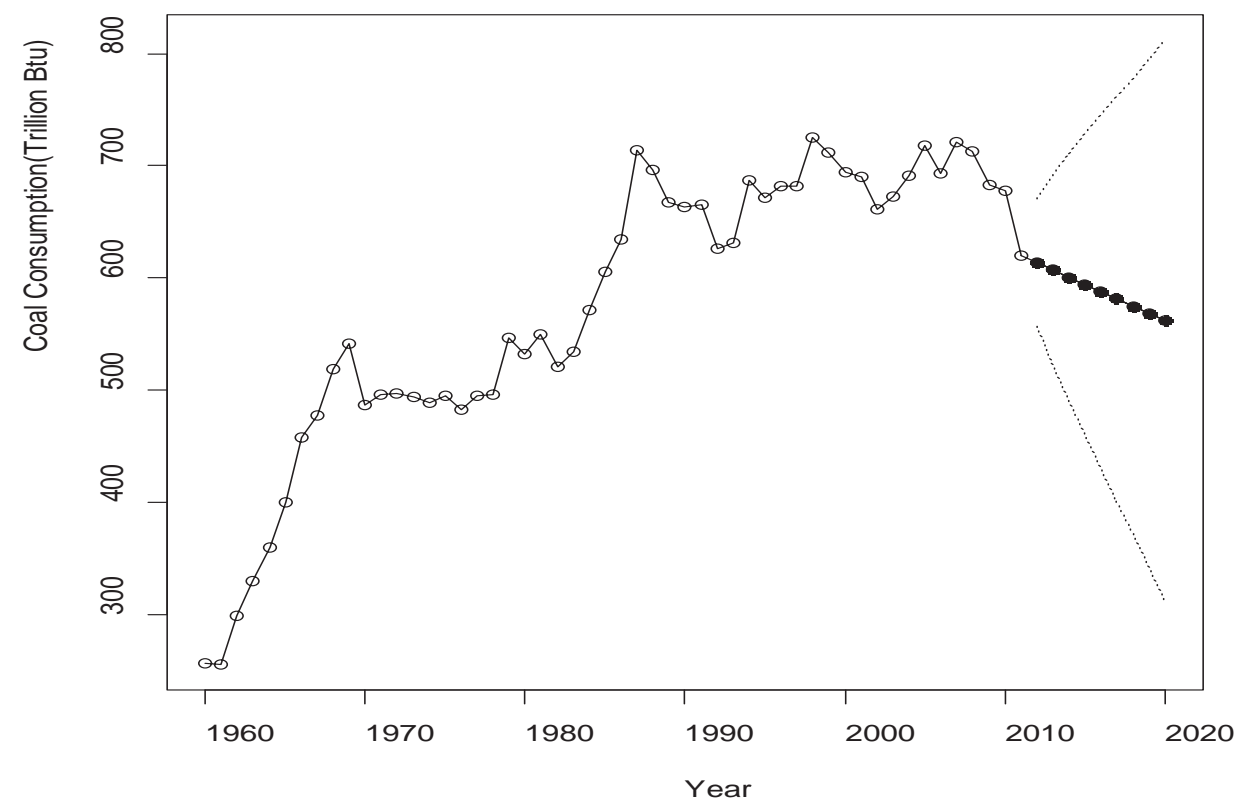

Figure 11: The Projection of Coal Consumption for Electricity Generation in Michigan 
The $\mathrm{CO}_{2}$ emission factors for coal can be found from EIA's FREQUENTLY ASKED QUESTIONS website ${ }^{9}$. This website provides the information of $\mathrm{CO}_{2}$ carbon emission factors for bituminous, sub-bituminous and lignite coal. The types and the total amount of coal consumed for electricity generation in Michigan in 2010 are available from American Lung Association (2011). Only Subbituminous and Bituminous coal are used for electricity generation in Michigan. Based on the proportion of individual coal needed for electricity production, the weighted $\mathrm{CO}_{2}$ emission factor can be calculated ${ }^{10}$. Multiplying the projected coal consumption by the weighted $\mathrm{CO}_{2}$ emission factor, the annual $\mathrm{CO}_{2}$ emission generated from coal-fired power plants from 2012 to 2020 can be calculated. The results are shown in Table 1.

\section{Table 1: The Predicted $\mathrm{CO}_{2}$ Emission from Coal-fired Power Plant under the Business as Usual Scenario}

\begin{tabular}{|c|c|c|}
\hline Year & $\begin{array}{c}\text { Coal Consumption } \\
\text { (Trillion BTU) }\end{array}$ & $\begin{array}{c}\text { CO2 Emission } \\
\text { (Billion lbs) }\end{array}$ \\
\hline 2012 & 613.88 & 126.52 \\
\hline 2013 & 607.36 & 125.18 \\
\hline 2014 & 600.84 & 123.83 \\
\hline 2015 & 594.32 & 122.49 \\
\hline 2016 & 587.80 & 121.15 \\
\hline 2017 & 581.28 & 119.80 \\
\hline 2018 & 574.76 & 118.46 \\
\hline 2019 & 568.24 & 117.11 \\
\hline 2020 & 561.72 & 115.77 \\
\hline
\end{tabular}

Source: Author's calculation.

\footnotetext{
${ }^{9}$ See http://www.eia.gov/tools/faqs/faq.cfm?id=74\&t=11, retrieved on March 30th, 2014. ${ }^{10}$ After the calculation, the total consumptions of subbituminous and bituminous coal are 29,201,133 and 3,484,589 tons, respectively. The $\mathrm{CO}_{2}$ emissions per million Btu of these two kinds of coal are 205.30 and $212.70 \mathrm{lbs}$. Thus, the weighted $\mathrm{CO}_{2}$ emission factor is $206.10 \mathrm{lbs}$ per million Btu of coal consumed for electricity production.
} 


\section{Chapter 4: Calculating $\mathrm{CO}_{2}$ Emission Reduction Cost}

\section{1 $\mathrm{CO}_{2}$ Emission Reductions under Different Scenarios}

Before estimating the cost of reducing $\mathrm{CO}_{2}$ emission in the existing coal-fired power plants in Michigan, it is necessary to determine the emission reduction targets. In this thesis, the mitigation costs of carbon emission reduction will be discussed under 3 scenarios. Reduction to $17 \%$ below $2005 \mathrm{CO}_{2}$ emission level by 2020 (17\% scenario), which is proposed by the Obama Administration, is regarded as the first scenario. Also, a progressive reduction target-30\% below 2005 level by 2020 (30\% scenario), and an even more challenging reduction target- 50\% below 2005 level by 2020 (50\% scenario) are used to estimate the potential cost under more stringent regulations. In April 2014, the EPA proposed a new $\mathrm{CO}_{2}$ emission standard for new coal and natural gas power plants. However, for the existing power plants, according to the timetable in the "Presidential Memorandum-Power Sector Carbon Pollution Standards", the final $\mathrm{CO}_{2}$ emission standards should be issued by June $1,2015^{11}$. It is uncertain whether the standards for existing power plants will be finally approved and when it will be implemented. This thesis assumes that it will be approved and implemented after 2015. The relevant time frame for this study is from 2016 to 2020 .

The future $\mathrm{CO}_{2}$ emissions in Michigan coal-fired power plants have been estimated in Chapter 3. The total amount of $\mathrm{CO}_{2}$ in Michigan's coal plants in the base

\footnotetext{
${ }^{11}$ See http://www.whitehouse.gov/the-press-office/2013/06/25/presidentialmemorandum-power-sector-carbon-pollution-standards, retrieved on Jan ${ }^{\text {th }}$, 2014.
} 
year (2005) can be calculated by multiplying the coal consumption for electricity production in that year (see Appendix A) by the $\mathrm{CO}_{2}$ emission factor (which is calculated in Chapter 3). From this calculation, the total $\mathrm{CO}_{2}$ emission generated from coal plants is about 148.02 billion lbs in 2005. To achieve the emission reduction goal, the $\mathrm{CO}_{2}$ emission generated from coal plants should be 122.86, 103.61 and 74.01 million lbs under $17 \%, 30 \%$ and $50 \%$ scenario by 2020 , respectively. In this thesis, it is assumed that the emission reduction targets would be achieved in 2020 under all the scenarios. Also, the annual emission target increases with the same growth rate in the individual scenario. The annual $\mathrm{CO}_{2}$ emission reduction targets in different scenarios are shown in the Table 2 .

The annual amount of $\mathrm{CO}_{2}$ emission from coal-fired plants is presented in Table 1. Also, the $\mathrm{CO}_{2}$ emission level in 2005 is known. Thus, the actual annual emission compared with 2005 level under the business-as-usual (BAU) scenario can be calculated. The results are also presented in Table 2 .

Table 2: Annual $\mathrm{CO}_{2}$ Emission Reduction Target and Actual Emission Reduction Compared with 2005 Level

\begin{tabular}{|c|c|c|c|c|}
\hline Year & $\begin{array}{c}\mathbf{1 7 \%} \\
\text { Scenario }\end{array}$ & $\begin{array}{c}\mathbf{3 0 \%} \\
\text { Scenario }\end{array}$ & $\begin{array}{c}\mathbf{5 0 \%} \\
\text { Scenario }\end{array}$ & $\begin{array}{c}\text { BAU } \\
\text { Scenario }\end{array}$ \\
\hline $\mathbf{2 0 1 5}$ & $17.25 \%$ & $17.25 \%$ & $17.25 \%$ & $17.25 \%$ \\
\hline $\mathbf{2 0 1 6}$ & $17.20 \%$ & $19.80 \%$ & $23.80 \%$ & $18.16 \%$ \\
\hline $\mathbf{2 0 1 7}$ & $17.15 \%$ & $22.35 \%$ & $30.35 \%$ & $19.06 \%$ \\
\hline $\mathbf{2 0 1 8}$ & $17.10 \%$ & $24.90 \%$ & $36.90 \%$ & $19.97 \%$ \\
\hline $\mathbf{2 0 1 9}$ & $17.05 \%$ & $27.45 \%$ & $43.45 \%$ & $20.88 \%$ \\
\hline $\mathbf{2 0 2 0}$ & $17.00 \%$ & $30.00 \%$ & $50.00 \%$ & $21.79 \%$ \\
\hline
\end{tabular}

Source: Author's calculation. 
Here are some explanations about the figure in Table 2. The annual increase in the emission reduction target under $17 \%, 30 \%$ and $50 \%$ scenarios can be calculated by the following equation:

Final Emission Target in 2020 - Emission Reduction Level in 2015 Year Period

For example, the annual increase of emission reduction target under the $17 \%$ scenario equals to $\frac{17 \%-11.4 \%}{5}=1.11 \%$.

Based on the results in Table 2, one can calculate the annual additional reduction requirements compared with the BAU scenario. The additional required amount of $\mathrm{CO}_{2}$ emission reduction can be estimated as well. The results are shown in Table 3 and Table 4 , respectively. The figures in the column of "17\% Scenario" in Table 3 are negative. That means the $\mathrm{CO}_{2}$ emission in coal-fired power plants from 2016 is lower than annual $17 \%$ emission reduction target. In other words, the $17 \%$ scenario target is achieved in 2016 instead of 2020. The absolute values of the negative figures in this column represent the addition emission reductions compared with emission reduction target in $17 \%$ scenario. According to the results in Table 4, from 2016 to 2020, a target of $30 \%$ and 50\% below $2005 \mathrm{CO}_{2}$ emission level can contribute to 36.47 and 125.28 billion $\mathrm{lbs}$ of $\mathrm{CO}_{2}$ emission reductions, respectively. Also, in the BAU scenario, 21.26 billion more lbs of $\mathrm{CO}_{2}$ are reduced when compared with target of $17 \%$ below 2005 emission level. 
Table 3: The Annual Additional Required $\mathrm{CO}_{2}$ Emission Reduction Compared with 2005 Level

\begin{tabular}{|c|c|c|c|}
\hline Year & $\begin{array}{c}\mathbf{1 7 \%} \\
\text { Scenario }\end{array}$ & $\begin{array}{c}\mathbf{3 0 \%} \\
\text { Scenario }\end{array}$ & $\begin{array}{c}\mathbf{5 0 \%} \\
\text { Scenario }\end{array}$ \\
\hline $\mathbf{2 0 1 6}$ & $-0.96 \%$ & $1.64 \%$ & $5.64 \%$ \\
\hline $\mathbf{2 0 1 7}$ & $-1.92 \%$ & $3.28 \%$ & $11.28 \%$ \\
\hline $\mathbf{2 0 1 8}$ & $-2.87 \%$ & $4.93 \%$ & $16.93 \%$ \\
\hline $\mathbf{2 0 1 9}$ & $-3.83 \%$ & $6.57 \%$ & $22.57 \%$ \\
\hline $\mathbf{2 0 2 0}$ & $-4.79 \%$ & $8.21 \%$ & $28.21 \%$ \\
\hline
\end{tabular}

Source: Author's calculation.

Table 4: The Additional Amount of $\mathrm{CO}_{2}$ Emission Reductions (Billion lbs)

\begin{tabular}{|c|c|c|c|}
\hline Year & $\begin{array}{c}\mathbf{1 7 \%} \\
\text { Scenario }\end{array}$ & $\begin{array}{c}\mathbf{3 0 \%} \\
\text { Scenario }\end{array}$ & $\begin{array}{c}\mathbf{5 0 \%} \\
\text { Scenario }\end{array}$ \\
\hline $\mathbf{2 0 1 6}$ & -1.42 & 2.43 & 8.35 \\
\hline $\mathbf{2 0 1 7}$ & -2.83 & 4.86 & 16.70 \\
\hline $\mathbf{2 0 1 8}$ & -4.25 & 7.29 & 25.06 \\
\hline $\mathbf{2 0 1 9}$ & -5.67 & 9.72 & 33.41 \\
\hline $\mathbf{2 0 2 0}$ & -7.09 & 12.16 & 41.76 \\
\hline Total & -21.26 & 36.47 & 125.28 \\
\hline
\end{tabular}

Source: Author's calculation.

\subsection{Cost Calculation of $\mathrm{CO}_{2}$ Emission Reduction}

This section will calculate the cost of replacing coal by other energy sources for electricity production. Initially, the replaced amount of electricity generated from coal should be known. Dividing the additional required amount of $\mathrm{CO}_{2}$ emission reduction in Table 4 by the $\mathrm{CO}_{2}$ emission factor for coal, the avoided amount of coal used for electricity generation is presented in Table 5. Based on the information in Table 3, no additional required $\mathrm{CO}_{2}$ emission reduction is needed under the $17 \%$ reduction target and 
Table 5: The Avoided Coal Consumption for Electricity Production (Trillions BTU)

\begin{tabular}{|c|c|c|}
\hline Year & $\begin{array}{c}\mathbf{3 0 \%} \\
\text { Scenario }\end{array}$ & $\begin{array}{c}\mathbf{5 0 \%} \\
\text { Scenario }\end{array}$ \\
\hline $\mathbf{2 0 1 6}$ & 11.80 & 40.52 \\
\hline $\mathbf{2 0 1 7}$ & 23.59 & 81.05 \\
\hline $\mathbf{2 0 1 8}$ & 35.39 & 121.57 \\
\hline $\mathbf{2 0 1 9}$ & 47.18 & 162.10 \\
\hline $\mathbf{2 0 2 0}$ & 58.98 & 202.62 \\
\hline
\end{tabular}

Source: Author's calculation.

no cost is need for $\mathrm{CO}_{2}$ reductions. Thus, this scenario will not be discussed in the following sections. The heat rate refers to the actual amount of fuel used for $1 \mathrm{kWh}$ electricity production. According to EIA's FREQUENTLY ASKED QUESTIONS website $^{12}$, the heat rate of coal is $10,498 \mathrm{Btu} / \mathrm{kwh}$. Thus, the avoided amount of electricity generation in the coal-fired power plants can be estimated by dividing the figures in Table 5 by the heat rate of coal. The results are shown in Table 6.

Table 6: The Avoided Electricity Generation in the Coal Plants (106 MWh)

\begin{tabular}{|c|c|c|}
\hline Year & $\begin{array}{c}30 \% \\
\text { Scenario } \\
\end{array}$ & $\begin{array}{c}\mathbf{5 0 \%} \\
\text { Scenario }\end{array}$ \\
\hline 2016 & 1.12 & 3.86 \\
\hline 2017 & 2.25 & 7.72 \\
\hline 2018 & 3.37 & 11.58 \\
\hline 2019 & 4.49 & 15.44 \\
\hline 2020 & 5.62 & 19.30 \\
\hline
\end{tabular}

Source: Author's calculation.

Various technologies are available to avoid carbon emissions in the electric power

${ }^{12}$ See http://www.eia.gov/tools/faqs/faq.cfm?id=667\&t=6, retrieved on April 10 ${ }^{\text {th }}, 2014$. 
sector. For example, $\mathrm{CO}_{2}$ capture and storage (CCS) technology can reduce large quantities of GHGs emission in fossil fuel power plants (IPCC 2005). However, there are some concerns about applying CCS. Despite of the critical requirements for geological storage, some other factors, such as the development of relevant laws and regulations, public acceptance, and $\mathrm{CO}_{2}$ transporting infrastructure, can influence the implement of CCS (Gibbins and Chalmers 2008). Currently, no power plant, which is over 100MW capability, has been put into practice (Rubin et al. 2007). In the industrial sector, increasing energy efficiency is regarded as one of the most important technologies to reduce GHG emissions in the short- to mid-term (Worrell et al. 2009).

Also, utilities can choose alternative energy resources, rather than fossil fuels, which have less or even no GHGs emissions. Renewable energy technology, such as solar energy and wind power, generates no GHGs during electricity production. Even considering the full life cycle of renewable energy technology, $\mathrm{CO}_{2}$ and other GHGs emissions per unit electricity generation are much lower than those from fossil fuel based power plants (Roth and Ambs 2004). According to the U.S. National Renewable Energy Laboratory ( Lopez et al. 2012), Michigan is abundant in renewable energy, especially solar and wind energy. However, most of the potential of hydropower has been tapped.

Like some renewable energy technologies, no air pollutants are emitted during electricity generation in nuclear power plants. Thus, replacing fossil fuels by nuclear energy can also contribute to reducing large quantities of GHGs emissions in the electric industry. However, despite the high capital cost of construction of a nuclear power plant, some other issues, including nuclear reactor safety, nuclear waste disposal, nuclear 
proliferation, should also be fully considered (Sailor et al. 2000).

Burning natural gas for electricity generation cannot avoid GHGs emission. However, burning coal can generate two times the $\mathrm{CO}_{2}$ emissions from burning natural gas when generating an equal amount of electricity (Epstein et al. 2011). Thus, replacing coal by natural gas for electricity production is one effective way to cut $\mathrm{CO}_{2}$ emissions considerably. Inevitably, generating electricity by burning biomass emits $\mathrm{CO}_{2}$. However, if biomass is managed properly, net emissions of $\mathrm{CO}_{2}$ can be neglected because the carbon is sequested by photosynthesis and returned to the atmosphere by combution (Gustavsson et al. 2007).

Although the $\mathrm{CO}_{2}$ emissions from burning oil is less than burning coal to produce electricity (Epstein et al. 2011), according to IEA's electricity Michigan profile, from 2006 to 2010 the annual share of electricity generated from petroleum is less than $0.1 \%$ of the total ${ }^{13}$.

This thesis only focuses on replacing coal by alternative energy resources to reduce $\mathrm{CO}_{2}$ emissions. Also, it is assumed that electricity providers will apply new power capacity to achieve annual $\mathrm{CO}_{2}$ reduction goals. Based on the above discussions, natural gas, nuclear energy, wind power, biomass and solar energy are selected as promising candidates to replace coal for electric generation to achieve the $\mathrm{CO}_{2}$ emission reduction targets under different scenarios. The rest of this chapter will estimate the total costs of generating electricity from these low-carbon emission energy sources instead of coal. By comparing costs, the most cost-effective technology is regarded as the best $\mathrm{CO}_{2}$

${ }^{13}$ See Table 5 on http://www.eia.gov/electricity/state/michigan/, retrieved on Jan $8^{\text {th }}$, 2014. 
mitigation strategy for coal-fired power plants.

Levelized cost of energy (LCE) approach attempts to incorporate all the aspects of electricity generation. Besides the utilization rate, it also considers all the following costs: the overnight capital cost, fuel cost, fixed and variable operation and maintenance cost, financing cost for different types of power plants (EIA 2011b; EIA 2012b; EIA 2013b; EIA 2014b). LCEs of different technologies under one plant type are available in EIA's "Levelized Cost of New Generation Resources" of the Annual Energy Outlook (AEO). The final decision of which technology in an individual plant would be applied for generating electricity is based on the "least cost" criteria. In other words, the electricity providers are always looking for the least-cost technology to produce electricity.

Subsidies for energy should be included to reflect the real cost of electricity production. Investment tax credit (ITC) can be regarded as a type of subsidy, which reduces the cost of electricity generation. ITC reduces $30 \%$ of capital expenditures for new solar PV power plant by the end of 2016. After 2016, it only covers $10 \%$ of the capital $\operatorname{cost}^{14}$. Production tax credit (PTC) works in the similar way. According to The Energy Policy Act of 2005, an advanced nuclear plant can receive \$18.0/MWh production tax credit ${ }^{15}$. The PTC for wind power and closed-loop biomass power plants is $2.3 \phi / \mathrm{kWh}$ if they start construction before the end of $2013^{16}$. Moreover, it is assumed

\footnotetext{
${ }^{14}$ See "Note 1" under Table 1 in "Levelized Cost of New Generation Resources in the Annual Energy Outlook 2014" (EIA 2014b). Retrieved from http://www.eia.gov/forecasts/aeo/pdf/electricity_generation.pdf on April 20th, 2014. 15 “ENERGY POLICY ACT (EPACT) OF 2005”. Retrieved from http://energy.gov/sites/prod/files/2013/10/f3/epact_2005.pdf on April 15th, 2014.

16 "Renewable Electricity Production Tax Credit (PTC)" Retrieved from http://dsireusa.org/incentives/incentive.cfm?Incentive_Code=US13F on April 15th, 2014.
} 
that generating electricity from biomass by close-loop technology will be used so that the biomass will be $\mathrm{CO}_{2}$ neutral.

The amount of $\mathrm{CO}_{2}$ emissions for natural gas combustion equals about half of the emissions of using coal to generate the same amount of electricity ${ }^{17}$. Undoubtedly, replacing coal by natural gas for electricity generation can help to reduce $\mathrm{CO}_{2}$ emissions, however, compared with the zero-emission technology (like solar and nuclear energy), it still contributes to carbon emission. Also, the impacts of the proposed carbon emission regulation on new power plants should be taken into consideration.

According to the EPA's latest proposed standards of greenhouse gas emissions regulation for new stationary sources, the amount of $\mathrm{CO}_{2}$ emission per $\mathrm{MWh}$ electricity generated from new larger natural gas power plants should be less than $1,000 \mathrm{lbs}$. The emission cap for a new smaller natural gas plant is $1,100 \mathrm{lbs} / \mathrm{MWh}$ (EPA 2013). It is uncertain whether or not the proposed the standard will be approved and when the standard will be enacted if it were approved. In this thesis, it is assumed that the new regulation will be implemented after 2015 .

Based on the "least cost" criteria, an advanced-combined-cycle natural gas plant is selected to be the best among the all the natural gas electric generation technologies from all the AEO references. The possible impacts of the proposed $\mathrm{CO}_{2}$ emission standard on the cost of generating electricity from new natural gas are not clear. To estimate the potential increase in the cost of electricity generated by natural gas, this thesis uses the following approaches. 2011, 2012, 2013 and 2014 Annual Energy Outlook

${ }^{17}$ See http://www.eia.gov/tools/faqs/faq.cfm?id=74\&t=11, retrieved on March 30th, 2014. 
references show a $3 \%$ increase in the capital cost considering the possible investments in greenhouse gas mitigation technologies adopted in coal power plants. Taking EPA's proposed $\mathrm{CO}_{2}$ emission regulation on new natural gas power plants into account, similarly, a 3\% point of capital cost is added to the LCE of natural gas power plant reflecting the new carbon emission regulation after 2015.

Based on the above discussion, the inflation adjusted LCEs of the selected electric generation technologies, including subsidies and $\mathrm{CO}_{2}$ emission cost under the proposed regulation, are shown in Table 7. The LCEs of power plants entering service in 2020 are not available, so the increasing or decreasing percentage of LCE from 2018 to 2019 is applied to predict the LCEs in 2020 for the each technology. 
Table 7: LCEs of Technologies Selected for Reducing $\mathrm{CO}_{2}$ Emission in Michigan

\begin{tabular}{|c|c|c|c|c|c|}
\hline Technology & $\begin{array}{c}\text { Entering } \\
\text { Service } \\
\text { Year }\end{array}$ & $\begin{array}{c}\text { Inflation } \\
\text { Adjusted LCE } \\
\text { (2009\$/MWh) }\end{array}$ & $\begin{array}{l}\text { LCE Before } \\
\text { Inflation } \\
\text { Adjusted } \\
\text { (\$/MWh) }\end{array}$ & $\begin{array}{l}\text { Subsidies/ } \\
\mathrm{CO}_{2} \text { Cost } \\
(\$ / \mathrm{MWh})\end{array}$ & $\begin{array}{c}\text { Cost Included } \\
\text { Subsidies and } \\
\mathrm{CO}_{2} \text { Cost } \\
(\$ / \mathrm{MWh})\end{array}$ \\
\hline \multirow{5}{*}{$\begin{array}{l}\text { Natural gas- } \\
\text { Advanced } \\
\text { Combined } \\
\text { Cycle }\end{array}$} & 2016 & 62.56 & 63.10 & 0.54 & 62.56 \\
\hline & 2017 & 61.59 & 63.10 & 0.53 & 62.58 \\
\hline & 2018 & 62.25 & 65.60 & 0.52 & 65.08 \\
\hline & 2019 & 59.89 & 64.40 & 0.47 & 63.93 \\
\hline & 2020 & 57.62 & N/A & N/A & N/A \\
\hline \multirow{5}{*}{$\begin{array}{l}\text { Advanced } \\
\text { Nuclear }\end{array}$} & 2016 & 95.90 & 113.90 & 18.00 & 95.90 \\
\hline & 2017 & 91.93 & 111.40 & 18.00 & 93.40 \\
\hline & 2018 & 86.47 & 108.40 & 18.00 & 90.40 \\
\hline & 2019 & 73.17 & 96.10 & 18.00 & 78.10 \\
\hline & 2020 & 61.92 & N/A & 18 & N/A \\
\hline \multirow{5}{*}{ Wind } & 2016 & 97.00 & 97.00 & 0 & 97.00 \\
\hline & 2017 & 94.49 & 96.00 & 0 & 96.00 \\
\hline & 2018 & 82.83 & 86.60 & 0 & 86.60 \\
\hline & 2019 & 75.23 & 80.30 & 0 & 80.30 \\
\hline & 2020 & 68.33 & N/A & 0 & N/A \\
\hline \multirow{5}{*}{ Solar PV } & 2016 & 152.32 & 210.70 & 58.38 & 152.32 \\
\hline & 2017 & 136.45 & 152.70 & 14.07 & 138.63 \\
\hline & 2018 & 125.55 & 144.30 & 13.04 & 131.26 \\
\hline & 2019 & 111.06 & 130.00 & 11.45 & 118.55 \\
\hline & 2020 & 98.24 & N/A & 0 & N/A \\
\hline \multirow{5}{*}{ Biomass } & 2016 & 112.50 & 112.50 & 0.00 & 112.50 \\
\hline & 2017 & 113.58 & 115.40 & 0.00 & 115.40 \\
\hline & 2018 & 106.17 & 111.00 & 0.00 & 111.00 \\
\hline & 2019 & 96.12 & 102.60 & 0.00 & 96.12 \\
\hline & 2020 & 87.02 & N/A & 0 & N/A \\
\hline
\end{tabular}

Sources: EIA 2011b; EIA 2012b; EIA 2013b; EIA 2014b.

Note: The 2020 inflation adjusted LCEs are estimated by the author based on the trends from 2018 to 2019. Except for the PTCs for some power plants are known, other data are not available. 


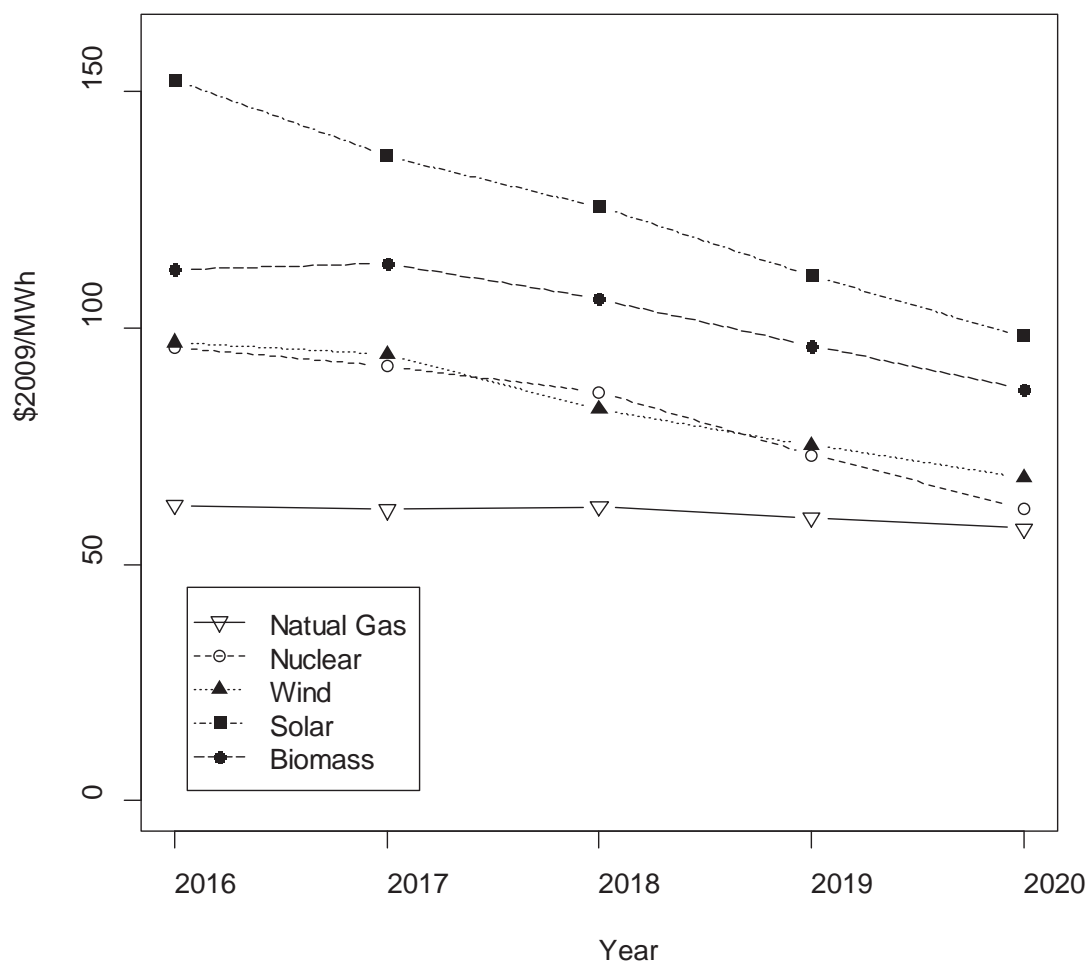

Figure 12: Annual LCEs for Different Types of Technology Applied for $\mathrm{CO}_{2}$ Emission Reduction in Michigan

To compare the electricity generation costs per unit of electricity generation, the annual LCEs of different types of power plants are plotted in Figure 12. Here are some other findings in Figure 12: 1) The LCE of each energy power plant has a clearly decreasing trend; 2) Although the per unit electric production cost of solar energy decreases the fastest among all the technologies, its cost is not comparative with natural gas and nuclear energy based power plants; 3) The cost of wind power plant is the lowest among all the renewable technologies. In 2018, the LCE of a wind power plant is even lower than nuclear energy power plant. It is clear that the LCEs for nuclear and wind power 
plants are very close. The possible reason for nuclear energy having a relatively lower LCE is that it benefits from PTC annually. For wind power plants, whether or not the current PTC for it will exist after 2015 is uncertain.

Thus, based on the information in Table 6 and 7, the costs of reducing $\mathrm{CO}_{2}$ emission by replacing coal by other energy sources can be easily calculated. The costs of using different kinds of energy under different scenarios are shown in Table 8. Figure 13 and 14 show the total costs of using alternative energy sources instead of coal to generate electricity to achieve $\mathrm{CO}_{2}$ emission reduction.

Based on the results in Table 8, the cost ranges of reducing $\mathrm{CO}_{2}$ emission in the coal-fired power plants in Michigan is from 1.01 to 1.95 billion dollars, 3.47 to 6.71 dollars in $30 \%$ scenario and 50\% scenario, respectively. Recall that the $17 \%$ target will be achieved by 2016, thus there is no investment needed for $\mathrm{CO}_{2}$ reduction in this scenario. According to Figure 13 and 14, in 30\% and 50\% scenarios, investing in natural gas power plants costs the least to achieve the goal of $\mathrm{CO}_{2}$ emission reduction by $30 \%$ and $50 \%$ below 2005 level in the coal plant in Michigan. This means generating electricity from natural gas should be taken as priority to reduce $\mathrm{CO}_{2}$ emission for electricity providers based on the least-cost criteria. 
Table 8: The Total Cost of Reducing $\mathrm{CO}_{2}$ Emission by Substituting Coal by Other Energy Sources (Million \$2009)

\begin{tabular}{|c|c|c|c|}
\hline Energy Source & Year & $\begin{array}{c}30 \% \\
\text { Scenario }\end{array}$ & $\begin{array}{c}50 \% \\
\text { Scenario }\end{array}$ \\
\hline \multirow{6}{*}{$\begin{array}{c}\text { Natural gas- } \\
\text { Advanced } \\
\text { Combined } \\
\text { Cycle }\end{array}$} & 2016 & 70.30 & 241.50 \\
\hline & 2017 & 138.41 & 475.49 \\
\hline & 2018 & 209.84 & 720.89 \\
\hline & 2019 & 269.18 & 924.74 \\
\hline & 2020 & 323.72 & $1,112.10$ \\
\hline & Total & $1,011.45$ & $3,474.73$ \\
\hline \multirow{6}{*}{$\begin{array}{c}\text { Advanced } \\
\text { Nuclear }\end{array}$} & 2016 & 107.76 & 370.19 \\
\hline & 2017 & 206.59 & 709.73 \\
\hline & 2018 & 291.48 & $1,001.37$ \\
\hline & 2019 & 328.87 & $1,129.79$ \\
\hline & 2020 & 347.86 & $1,195.02$ \\
\hline & Total & $1,282.56$ & $4,406.10$ \\
\hline \multirow{6}{*}{ Wind } & 2016 & 108.99 & 374.44 \\
\hline & 2017 & 212.35 & 729.49 \\
\hline & 2018 & 279.21 & 959.21 \\
\hline & 2019 & 338.13 & $1,161.60$ \\
\hline & 2020 & 383.88 & $1,318.77$ \\
\hline & Total & $1,322.56$ & $4,543.52$ \\
\hline \multirow{6}{*}{ Solar PV } & 2016 & 171.15 & 587.98 \\
\hline & 2017 & 306.64 & $1,053.44$ \\
\hline & 2018 & 423.22 & $1,453.93$ \\
\hline & 2019 & 499.17 & $1,714.84$ \\
\hline & 2020 & 551.95 & $1,896.16$ \\
\hline & Total & $1,952.13$ & $6,706.35$ \\
\hline \multirow{6}{*}{ Biomass } & 2016 & 126.41 & 434.27 \\
\hline & 2017 & 255.25 & 876.87 \\
\hline & 2018 & 357.89 & $1,229.50$ \\
\hline & 2019 & 432.02 & $1,484.16$ \\
\hline & 2020 & 488.90 & $1,679.58$ \\
\hline & Total & $1,660.47$ & $5,704.38$ \\
\hline
\end{tabular}

Source: Authors calculation. 


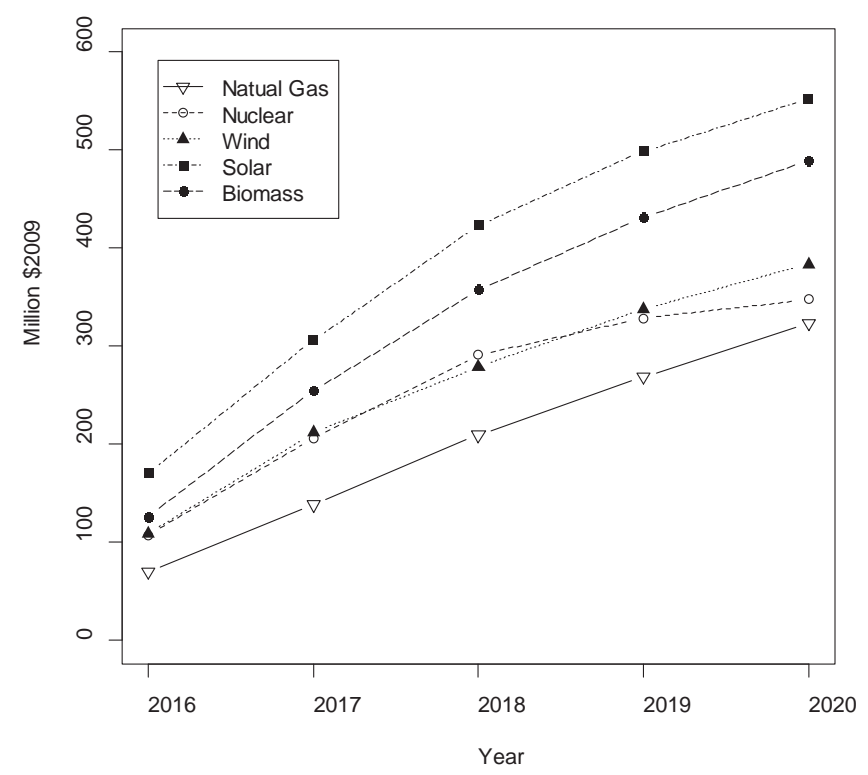

Figure 13: Total Cost of $\mathrm{CO}_{2}$ Emission Reduction Technologies under the 30\% Scenario

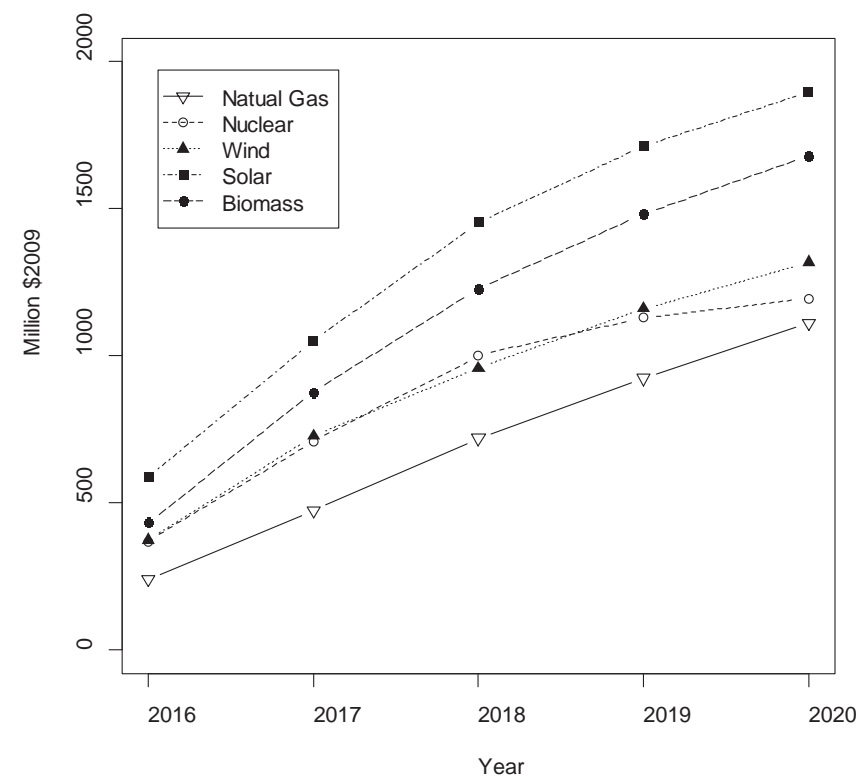

Figure 14: Total Cost of $\mathrm{CO}_{2}$ Emission Reduction Technologies under the 50\% Scenario 


\section{Chapter 5: Discussion}

The $\mathrm{CO}_{2}$ reduction costs of different technology-based power plants under three scenarios- 17\%, 30\% and 50\% below 2005 emission levels- are calculated in Chapter 5. According to the results, it is found that generating electricity from advanced-combinedcycle natural gas power plant instead of coal plant is the least cost way to achieve annual $\mathrm{CO}_{2}$ emission reduction goals in the $30 \%$ and $50 \%$ scenarios. Although no $\mathrm{CO}_{2}$ emission is generated during renewable electricity production, the projected future LCEs of a renewable electric power plant cannot compete with natural gas power plant. For example, according to Table 7, the annual LCEs of a solar PV power plant is about as twice as much that a natural gas power plant.

The estimation of LECs is based on the current subsidy policies for different electric production technologies. As discussed in Chapter 4, the PTC for a wind power and closed-loop biomass power plant can have a $2.3 \notin / \mathrm{kWh}$ PTC if they are under construction by the end of 2013. However, an advanced nuclear power plant can receive an $\$ 18.0 / \mathrm{MWh}$ PTC and there is no expiration date for that. This PTC makes the LCE of nuclear power plant lower than biomass energy and wind power plants in specific years (See Table 7). It is uncertain whether or not the wind power and biomass based power plants can continue to benefit from the current PTC policy after 2015. This chapter will compare the costs of $\mathrm{CO}_{2}$ emission reduction technologies assuming the current PTCs for wind and biomass would not change from 2016 to 2020. 
Another issue of generating electricity from renewable energy is the intermittency feature of some renewable energy technologies. Wind power electric production can be influenced by the speed of the wind and electricity generated from solar energy is limited by the sufficiency of the sunlight. The intermittency factor is not included in LCEs of wind and solar energy power plants in Chapter 5. What the cost would be if the intermittency of renewable energy taken into consideration will be also discussed in this Chapter.

\section{1 The Impacts of the PTC on the Cost of $\mathrm{CO}_{2}$ Emission Reduction Technologies}

It is assumed that close-loop biomass power plants and wind power plants will continue to have a $2.3 \notin / \mathrm{kWh}$ PTC after 2015. The LCEs of alternative electric production technologies to reduce $\mathrm{CO}_{2}$ emission in Michigan coal plants are shown in Table 9. Figure 15 shows the time series plot of LCEs of different electricity generation technologies if the PTCs for biomass energy and wind power plants continue in the future. 
Table 9: LCEs of Technologies Selected for Reducing $\mathrm{CO}_{2}$ Emission in Michigan Assuming PTCs for Wind Power and Biomass Power Plants Continue

\begin{tabular}{|c|c|c|c|c|c|}
\hline Technology & $\begin{array}{c}\text { Entering } \\
\text { Service } \\
\text { Year }\end{array}$ & $\begin{array}{c}\text { Inflation } \\
\text { Adjusted } \\
\text { LCE } \\
\text { (2009\$/MWh) }\end{array}$ & $\begin{array}{l}\text { LCE Before } \\
\text { Inflation } \\
\text { Adjusted } \\
\text { (\$/MWh) } \\
\end{array}$ & $\begin{array}{l}\text { Subsidies/ } \\
\mathrm{CO}_{2} \text { Cost } \\
(\$ / \mathrm{MWh})\end{array}$ & $\begin{array}{c}\text { Cost } \\
\text { Included } \\
\text { Subsidies and } \\
\mathrm{CO}_{2} \mathrm{Cost} \\
(\$ / \mathrm{MWh}) \\
\end{array}$ \\
\hline \multirow{5}{*}{$\begin{array}{l}\text { Natural } \\
\quad \text { gas- } \\
\text { Advanced } \\
\text { Combined } \\
\quad \text { Cycle }\end{array}$} & 2016 & 62.56 & 63.10 & 0.54 & 62.56 \\
\hline & 2017 & 61.59 & 63.10 & 0.53 & 62.58 \\
\hline & 2018 & 62.25 & 65.60 & 0.52 & 65.08 \\
\hline & 2019 & 59.89 & 64.40 & 0.47 & 63.93 \\
\hline & 2020 & 57.62 & N/A & N/A & N/A \\
\hline \multirow{5}{*}{$\begin{array}{l}\text { Advanced } \\
\text { Nuclear }\end{array}$} & 2016 & 95.90 & 113.90 & 18.00 & 95.90 \\
\hline & 2017 & 91.93 & 111.40 & 18.00 & 93.40 \\
\hline & 2018 & 86.47 & 108.40 & 18.00 & 90.40 \\
\hline & 2019 & 73.17 & 96.10 & 18.00 & 78.10 \\
\hline & 2020 & 61.92 & N/A & 18.00 & N/A \\
\hline \multirow{5}{*}{ Wind } & 2016 & 74.00 & 97.00 & 23.00 & 74.00 \\
\hline & 2017 & 71.85 & 96.00 & 23.00 & 73.00 \\
\hline & 2018 & 60.83 & 86.60 & 23.00 & 63.60 \\
\hline & 2019 & 53.68 & 80.30 & 23.00 & 57.30 \\
\hline & 2020 & 47.37 & N/A & 23.00 & N/A \\
\hline \multirow{5}{*}{ Solar PV } & 2016 & 152.32 & 210.70 & 58.38 & 152.32 \\
\hline & 2017 & 136.45 & 152.70 & 14.07 & 138.63 \\
\hline & 2018 & 125.55 & 144.30 & 13.04 & 131.26 \\
\hline & 2019 & 111.06 & 130.00 & 11.45 & 118.55 \\
\hline & 2020 & 98.24 & N/A & N/A & N/A \\
\hline \multirow{5}{*}{ Biomass } & 2016 & 89.50 & 112.50 & 23.00 & 89.50 \\
\hline & 2017 & 90.94 & 115.40 & 23.00 & 92.40 \\
\hline & 2018 & 84.17 & 111.00 & 23.00 & 88.00 \\
\hline & 2019 & 74.57 & 102.60 & 23.00 & 79.60 \\
\hline & 2020 & 66.06 & N/A & 23.00 & N/A \\
\hline
\end{tabular}

Source: Author's calculation.

Note: The 2020 inflation adjusted LCEs are estimated by the author based on the trends from 2018 to 2019. Except for the PTCs for some power plants are known, other data are not available. 


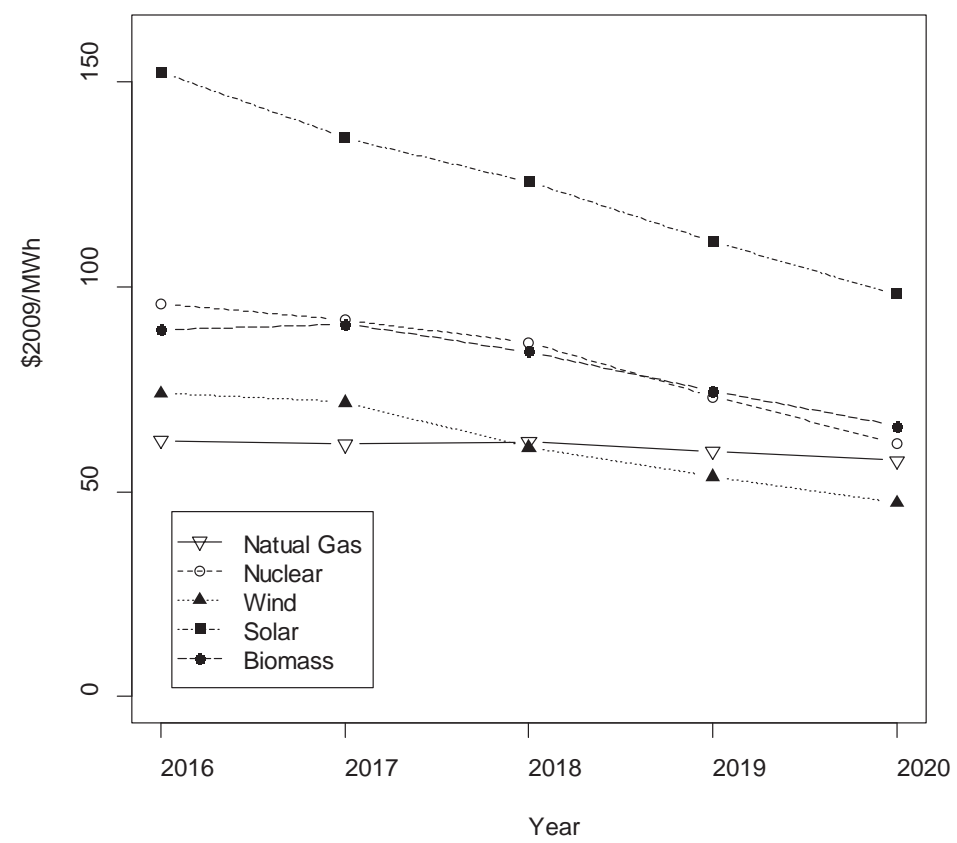

Figure 15: Annual LCEs for Different Types of Technology for $\mathrm{CO}_{2}$ Emission Reduction in Michigan if the PTCs for Biomass Energy and Wind Power Plants Continue after 2015.

Comparing Figure 15 with Figure 12, there are some interesting findings: 1) the decreasing trends of all the LCEs do not change; 2) the LCEs of wind and biomass power plants become competitive if a $2.3 \notin / \mathrm{kWh}$ PTC continue after 2016; 3) The LCE of biomass power plants is lower than nuclear power plant before 2019. If the PTC does not continue, then the cost of a biomass power plant is always higher than that of a nuclear power plant; 4) Benefiting from the PTC, the LCE of wind power energy becomes lower than that of an advanced-combined-cycle natural gas power plant after 2017. Based on the above findings, it is safe to conclude that PTCs for renewable energy projects have influential impacts on the cost of electricity generation from these sources. The existence 
of PTC makes the cost of electricity generated from renewable energy more competitive with natural gas and nuclear power plants.

Changes in LCEs will result in the changes of total costs of electric generation from different technologies. The total cost under 30\% and 50\% scenarios will be estimated as follows. Using the same approach as in Chapter 4, one can calculate the total costs by multiplying per unit cost of electricity production in Table 9 by the avoided electric production from coal-fired power plants for $\mathrm{CO}_{2}$ emission reduction in Table 6. The results are presented in Table 10. Figure 16 and 17 are the time series plots of results in Table 10.

If the current PTCs for wind power and biomass energy continue after 2015 and if coal is replaced by only one type of energy resource for $\mathrm{CO}_{2}$ emission reduction, the cost range is from 957.08 million to 1.95 billion dollars, 3.29 to 6.71 billion dollars in $30 \%$ scenario and 50\% scenario, respectively. In all the scenarios, wind power energy becomes the least-cost electric generation technology to reduce $\mathrm{CO}_{2}$ in the power plants of Michigan. When comparing results in Table 8 and Table 10, wind power takes the place of advanced-combined-circle natural gas power plants to become the primary strategy to achieve $\mathrm{CO}_{2}$ emission reduction goals. 
Table 10: The Total Cost of Reducing $\mathrm{CO}_{2}$ Emission by Substituting Coal by Other Energy Sources if PTC for Wind Power and Biomass Power Plants Continue (Million \$2009)

\begin{tabular}{|c|c|c|c|}
\hline Energy Source & Year & $\begin{array}{c}30 \% \\
\text { Scenario }\end{array}$ & $\begin{array}{c}\mathbf{5 0 \%} \\
\text { Scenario }\end{array}$ \\
\hline \multirow{6}{*}{$\begin{array}{l}\text { Natural gas- } \\
\text { Advanced } \\
\text { Combined } \\
\text { Cycle }\end{array}$} & 2016 & 70.30 & 241.50 \\
\hline & 2017 & 138.41 & 475.49 \\
\hline & 2018 & 209.84 & 720.89 \\
\hline & 2019 & 269.18 & 924.74 \\
\hline & 2020 & 323.72 & $1,112.10$ \\
\hline & Total & $1,011.45$ & $3,474.73$ \\
\hline \multirow{6}{*}{$\begin{array}{c}\text { Advanced } \\
\text { Nuclear }\end{array}$} & 2016 & 107.76 & 370.19 \\
\hline & 2017 & 206.59 & 709.73 \\
\hline & 2018 & 291.48 & $1,001.37$ \\
\hline & 2019 & 328.87 & $1,129.79$ \\
\hline & 2020 & 347.86 & $1,195.02$ \\
\hline & Total & $1,282.56$ & $4,406.10$ \\
\hline \multirow{6}{*}{ Wind } & 2016 & 83.15 & 285.65 \\
\hline & 2017 & 161.47 & 554.71 \\
\hline & 2018 & 205.05 & 704.44 \\
\hline & 2019 & 241.27 & 828.85 \\
\hline & 2020 & 266.14 & 914.29 \\
\hline & Total & 957.08 & $3,287.94$ \\
\hline \multirow{6}{*}{ Solar PV } & 2016 & 171.15 & 587.98 \\
\hline & 2017 & 306.64 & $1,053.44$ \\
\hline & 2018 & 423.22 & $1,453.93$ \\
\hline & 2019 & 499.17 & $1,714.84$ \\
\hline & 2020 & 551.95 & $1,896.16$ \\
\hline & Total & $1,952.13$ & $6,706.35$ \\
\hline \multirow{6}{*}{ Biomass } & 2016 & 100.57 & 345.48 \\
\hline & 2017 & 204.37 & 702.09 \\
\hline & 2018 & 283.73 & 974.73 \\
\hline & 2019 & 335.16 & $1,151.41$ \\
\hline & 2020 & 371.17 & $1,275.11$ \\
\hline & Total & $1,294.99$ & $4,448.82$ \\
\hline
\end{tabular}

Source: Author's calculation. 


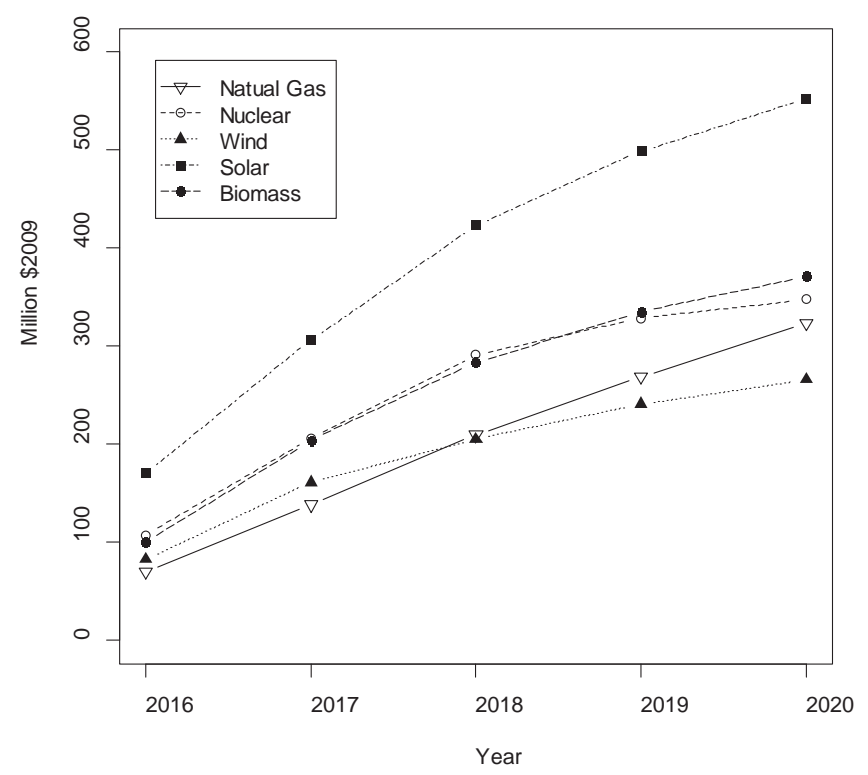

Figure 16 : Total Cost of $\mathrm{CO}_{2}$ Emission Reduction Technologies under the $30 \%$ Scenario (If PTCs for Biomass Energy and Wind Power Plants Continue after 2015).

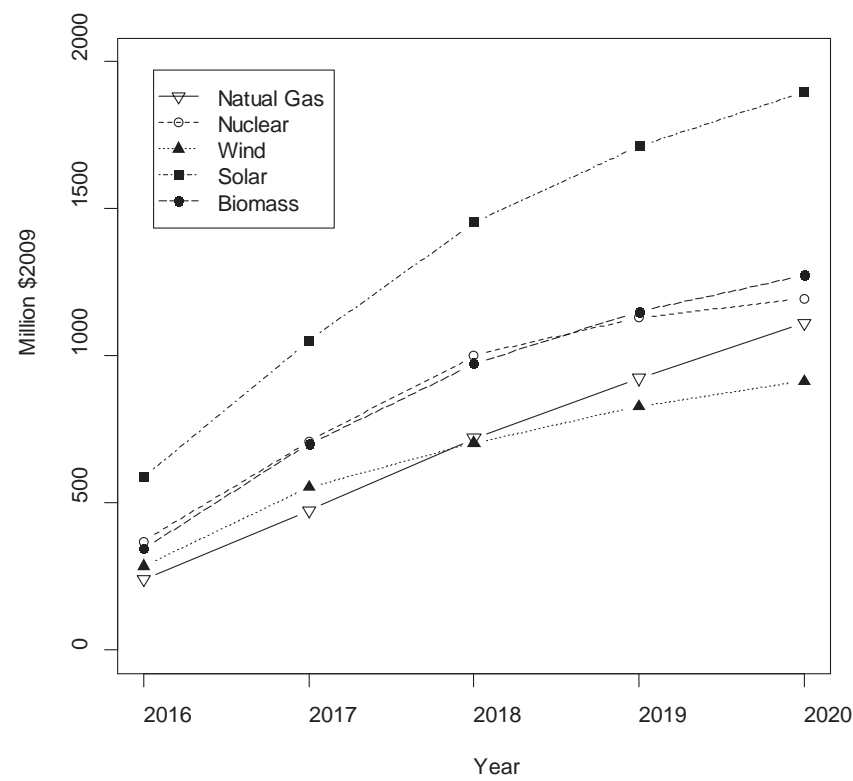

Figure 17: Total Cost of $\mathrm{CO}_{2}$ Emission Reduction Technologies under the 50\% Scenario (If PTCs for Biomass Energy and Wind Power Plants Continue after 2015). 
Comparing Figure 16 and 17 with their counterparts in Chapter 4, the existence of PTC has influential impacts on the total costs of $\mathrm{CO}_{2}$ mitigation technologies. The total cost of a biomass power plant is always higher than a nuclear power plant if there is no PTC in the future. However, benefiting from the PTC, the total costs of replacing coal by biomass to avoid $\mathrm{CO}_{2}$ emissions in the electric power sector are lower than by using nuclear energy from 2016 to 2018 . After 2018, the total cost of generating electricity from biomass power plant becomes higher than for a nuclear power plant. Also, for wind power plants, the total costs in the initial years (in 2016 and 2017) are higher than natural gas power plants. The turning point is 2018. From 2018, the total cost of wind power energy is competitive with not only a natural gas power plant but also all the other electric generation technologies. Recall that the total costs of natural gas power plants are lower than any other types of power plants if the PTC for wind power plants doesn't exist.

If the current PTCs for wind and biomass energy power plants still exists from 2016 to 2020, a combination strategy (applying natural gas and wind power technologies) for $\mathrm{CO}_{2}$ emission reduction is the least-cost strategy based on the time series plots of total costs of electricity generation technology in Figure 16 and 17. In all these two scenarios, the electricity provider should substitute coal by natural gas to avoid $\mathrm{CO}_{2}$ emissions from 2016 to 2017. For the total cost of wind power plant becomes lower than other types of power plants, from 2018 wind power will be the best candidate to replace coal for electricity generation. After calculations, the total costs of applying the combination of technologies to reducing $\mathrm{CO}_{2}$ emission in coal-fired power plants are 921.17 million dollars and 3.16 billion dollars in the $30 \%$ and $50 \%$ scenario, respectively. 


\subsection{The Impacts of the Intermittency of Renewable Energy}

Wind power and solar energy are intermittent renewable energy. These electric generation technologies are not continuously available and dispatchable. Also, they are unpredictable and variable. Electricity production in wind farms is limited by the speed of the wind, and solar electricity generation is highly influenced by solar radiation. The intermittency feature of renewable energy has negative impacts on the electric grid systems, which should be considered when estimating the cost of electric generation from wind power and solar energy.

Much research has been done to study the actual cost of intermittency. Smith et al. (2004) made a summary of studies of the impacts of wind power on the operating costs of electric power system. They concluded that about at $5 \%$ or less wind penetration, the impact of wind power is small. If the wind power can meet 50 percent of demand, the cost of intermittency is $1-2 \phi / \mathrm{kWh}$ (DeCarolis and Keith 2005). Without sunshine at night, the users of large and utility scale solar PV systems must use additional generating units or the grid to acquire electricity (Sovacool 2009). Gowrisankaran et al. (2011) estimated that the welfare loss of unforecastable intermittency associated with a $20 \%$ solar photovoltaic mandate is $3 \%$ of the cost of solar energy. Based on the above studies, this thesis makes the following assumptions: $1 \notin / \mathrm{kWh}$ and $2 \phi / \mathrm{kWh}$ cost of intermittency are added to the LCE of wind power plant in the $30 \%$ and $50 \%$ scenarios. $3 \%$ of cost is imposed on the solar energy technology to reflect the welfare loss of intermittency. After calculation, the costs of generating electricity from solar energy and wind power, which include the intermittency costs, are shown in Table 11. 
Table 11: LCEs of Wind and Solar Power Plant Including the Cost of Intermittency (Excluding PTCs for Wind and Biomass Power Plants) (2009\$/MWh)

\begin{tabular}{|c|c|c|c|}
\hline Technology & Year & $\begin{array}{c}\mathbf{3 0 \%} \\
\text { Scenario }\end{array}$ & $\begin{array}{c}50 \% \\
\text { Scenario }\end{array}$ \\
\hline \multirow{5}{*}{ Wind } & 2016 & 107.00 & 117.00 \\
\hline & 2017 & 104.33 & 114.17 \\
\hline & 2018 & 92.40 & 101.96 \\
\hline & 2019 & 84.60 & 93.96 \\
\hline & 2020 & 77.46 & 86.59 \\
\hline \multirow{5}{*}{ Solar PV } & 2016 & 156.89 & 156.89 \\
\hline & 2017 & 140.54 & 140.54 \\
\hline & 2018 & 129.32 & 129.32 \\
\hline & 2019 & 114.40 & 114.40 \\
\hline & 2020 & 101.20 & 101.20 \\
\hline
\end{tabular}

Source: Author's calculation.

Definitely, adding the cost of intermittency to wind and solar energy power plants does not impact the cost of other electric production technologies. Using the same approach in Chapter 4, the total cost of replacing coal by other low-carbon emission energy sources, which includes the intermittency cost, can be calculated. The results are shown in Table 12. If considering the cost of intermittency, the cost range is from 1.01 to 2.01 billion dollars and 3.47 to 6.91 billion dollars in the $30 \%$ and $50 \%$ scenario, respectively. Building natural-gas power plants for $\mathrm{CO}_{2}$ emission reduction is least cost way in all the scenarios. Using solar energy to replace coal to generate electricity will be the most expensive option. One can compare the cost trend of individual $\mathrm{CO}_{2}$ mitigation technologies using the time series plots are shown in Figure 18 and 19. 
Table 12: The Cost of Reducing $\mathrm{CO}_{2}$ Emission by Substituting Coal by Other Energy Sources Including the Cost of Intermittency (Excluding PTCs for Wind and Biomass Power Plants) (Million \$2009)

\begin{tabular}{|c|c|c|c|}
\hline Energy Source & Year & $\begin{array}{c}30 \% \\
\text { Scenario }\end{array}$ & $\begin{array}{c}\mathbf{5 0 \%} \\
\text { Scenario }\end{array}$ \\
\hline \multirow{6}{*}{$\begin{array}{l}\text { Natural gas- } \\
\text { Advanced } \\
\text { Combined } \\
\text { Cycle }\end{array}$} & 2016 & 70.30 & 241.50 \\
\hline & 2017 & 138.41 & 475.49 \\
\hline & 2018 & 209.84 & 720.89 \\
\hline & 2019 & 269.18 & 924.74 \\
\hline & 2020 & 323.72 & $1,112.10$ \\
\hline & Total & $1,011.45$ & $3,474.73$ \\
\hline \multirow{6}{*}{$\begin{array}{l}\text { Advanced } \\
\text { Nuclear }\end{array}$} & 2016 & 107.76 & 370.19 \\
\hline & 2017 & 206.59 & 709.73 \\
\hline & 2018 & 291.48 & $1,001.37$ \\
\hline & 2019 & 328.87 & $1,129.79$ \\
\hline & 2020 & 347.86 & $1,195.02$ \\
\hline & Total & $1,282.56$ & $4,406.10$ \\
\hline \multirow{6}{*}{ Wind } & 2016 & 120.23 & 451.64 \\
\hline & 2017 & 234.46 & 881.43 \\
\hline & 2018 & 311.47 & $1,180.75$ \\
\hline & 2019 & 380.24 & $1,450.80$ \\
\hline & 2020 & 435.18 & $1,671.21$ \\
\hline & Total & $1,481.58$ & $5,635.83$ \\
\hline \multirow{6}{*}{ Solar PV } & 2016 & 176.29 & 605.62 \\
\hline & 2017 & 315.83 & $1,085.01$ \\
\hline & 2018 & 435.93 & $1,497.59$ \\
\hline & 2019 & 514.18 & $1,766.41$ \\
\hline & 2020 & 568.57 & $1,953.27$ \\
\hline & Total & $2,010.80$ & $6,907.90$ \\
\hline \multirow{6}{*}{ Biomass } & 2016 & 126.41 & 434.27 \\
\hline & 2017 & 255.25 & 876.87 \\
\hline & 2018 & 357.89 & $1,229.50$ \\
\hline & 2019 & 432.02 & $1,484.16$ \\
\hline & 2020 & 488.90 & $1,679.58$ \\
\hline & Total & $1,660.47$ & $5,704.38$ \\
\hline
\end{tabular}

Source: Author's calculation. 


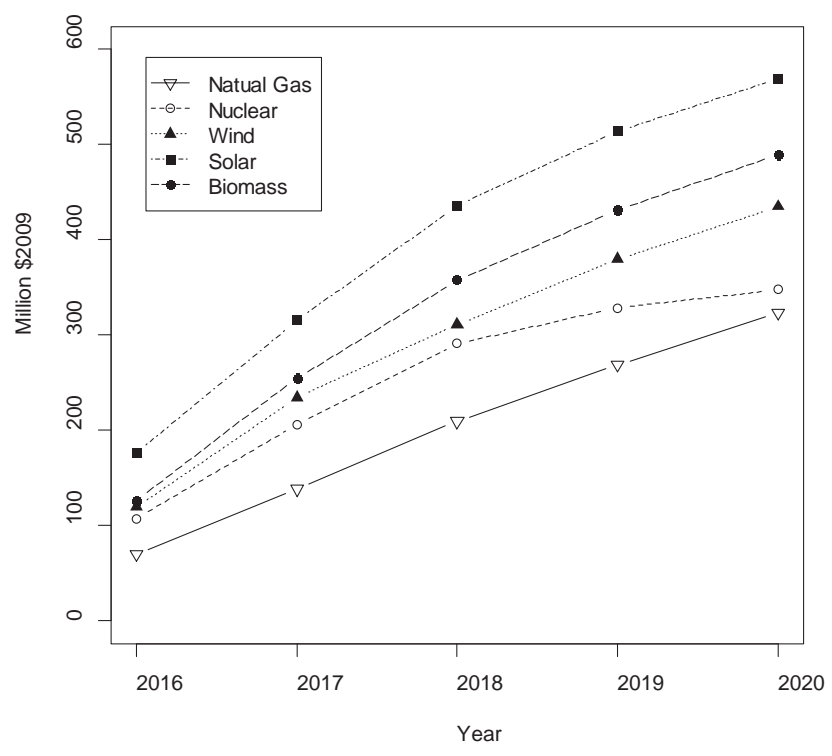

Figure 18: Total Cost of $\mathrm{CO}_{2}$ Emission Reduction Technologies under the 30\% Scenario without PTCs for Wind and Solar Power Plants (Including the Cost of Intermittency of Wind Power and Solar Energy).

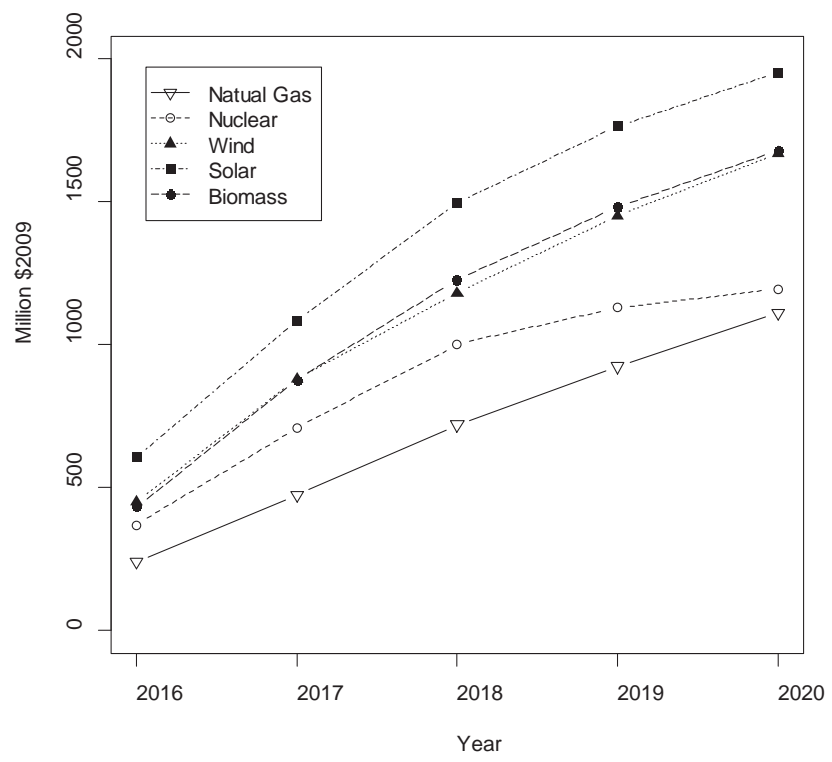

Figure 19: Total Cost of $\mathrm{CO}_{2}$ Emission Reduction Technologies under the 50\% Scenario without PTCs for Wind and Biomass Power Plants (Including the Cost of Intermittency of Wind Power and Solar Energy). 
The above analysis does not take the future possible PTC policies for wind and biomass power plants into account. In Section 5.1, PTC decreases the cost of renewable electricity generation significantly. Whether the PTC would exist or not has great impacts on the cost analysis of $\mathrm{CO}_{2}$ emission reduction technologies and the final results. Table 13 shows the results of cost of $\mathrm{CO}_{2}$ mitigation technologies, which includes the cost of intermittency and assumes that the current PTCs for wind power and biomass energy plants will not change after 2015. If considering replacing coal by only one technology to generate electricity, the cost range under $30 \%$ and $50 \%$ scenario varies from 1.01 to 2.01 billion dollars and 3.47 to 6.91 billion dollars, respectively. The cost range in each scenario is the same with its counterpart in Table 12. The time series plot of the cost of different $\mathrm{CO}_{2}$ mitigation technologies are shown in Figure 20 and 21. 
Table 13: The Cost of Reducing $\mathrm{CO}_{2}$ Emission Technologies Including the PTCs for Wind Power and Biomass Energy Plant After 2015 (Cost of Intermittency Included) (Million \$2009)

\begin{tabular}{|c|c|c|c|}
\hline Energy Source & Year & $\begin{array}{c}\mathbf{3 0 \%} \\
\text { Scenario }\end{array}$ & $\begin{array}{c}\mathbf{5 0 \%} \\
\text { Scenario }\end{array}$ \\
\hline \multirow{6}{*}{$\begin{array}{l}\text { Natural gas- } \\
\text { Advanced } \\
\text { Combined } \\
\text { Cycle }\end{array}$} & 2016 & 70.30 & 241.49 \\
\hline & 2017 & 138.41 & 475.49 \\
\hline & 2018 & 209.84 & 720.89 \\
\hline & 2019 & 269.18 & 924.74 \\
\hline & 2020 & 323.72 & $1,112.11$ \\
\hline & Total & $1,011.45$ & $3,474.73$ \\
\hline \multirow{6}{*}{$\begin{array}{l}\text { Advanced } \\
\text { Nuclear }\end{array}$} & 2016 & 107.76 & 370.19 \\
\hline & 2017 & 206.59 & 709.73 \\
\hline & 2018 & 291.48 & $1,001.37$ \\
\hline & 2019 & 328.87 & $1,129.79$ \\
\hline & 2020 & 347.88 & $1,195.11$ \\
\hline & Total & $1,282.58$ & $4,406.18$ \\
\hline \multirow{6}{*}{ Wind } & 2016 & 94.39 & 362.86 \\
\hline & 2017 & 183.58 & 706.72 \\
\hline & 2018 & 237.31 & 925.98 \\
\hline & 2019 & 283.38 & $1,118.21$ \\
\hline & 2020 & 317.25 & $1,265.96$ \\
\hline & Total & $1,115.91$ & $4,379.72$ \\
\hline \multirow{6}{*}{ Solar PV } & 2016 & 176.29 & 605.62 \\
\hline & 2017 & 315.83 & $1,085.01$ \\
\hline & 2018 & 435.93 & $1,497.59$ \\
\hline & 2019 & 514.18 & $1,766.26$ \\
\hline & 2020 & 568.57 & $1,952.93$ \\
\hline & Total & $2,010.80$ & $6,907.41$ \\
\hline \multirow{6}{*}{ Biomass } & 2016 & 100.57 & 345.48 \\
\hline & 2017 & 204.37 & 702.09 \\
\hline & 2018 & 283.73 & 974.73 \\
\hline & 2019 & 335.16 & $1,151.41$ \\
\hline & 2020 & 371.17 & $1,275.11$ \\
\hline & Total & $1,294.99$ & $4,448.82$ \\
\hline
\end{tabular}

Source: Author's calculation. 


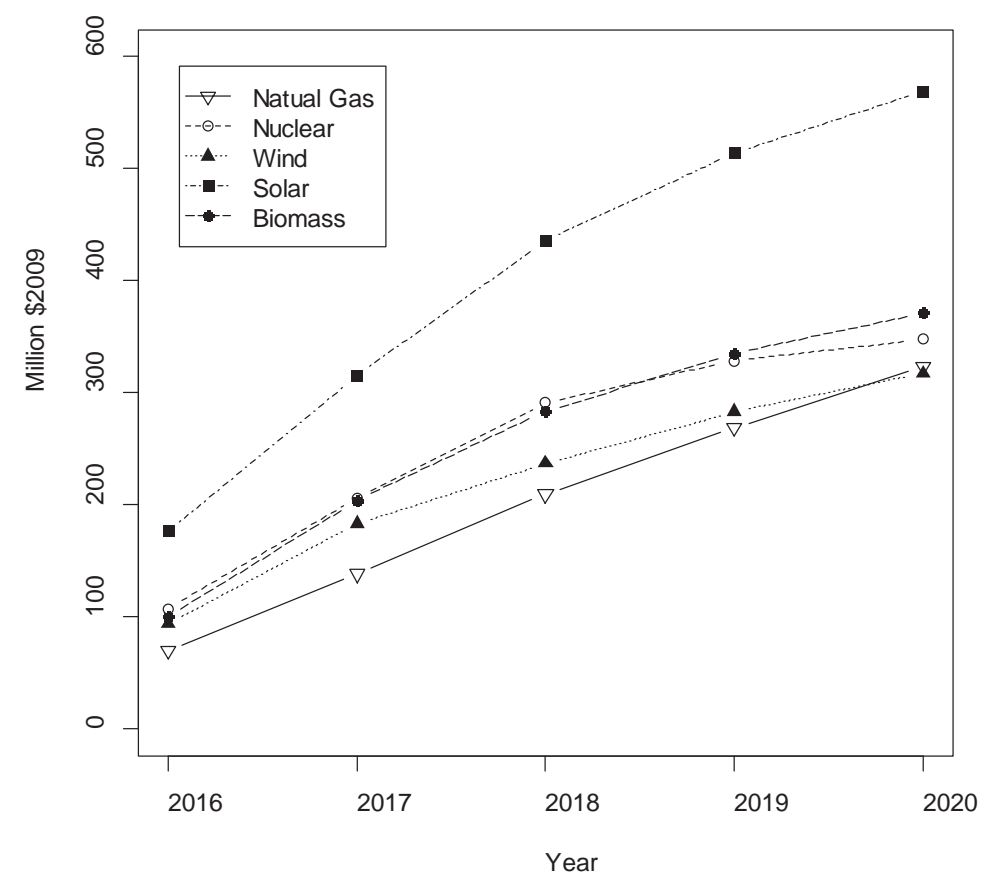

Figure 20: Total Cost of $\mathrm{CO}_{2}$ Emission Reduction Technologies under the 30\% Scenario (The Current PTCs for Wind and Biomass will not Change after 2015 and the Cost of Intermittency is Included).

Based on the plots in Figure 20, one can conclude that from 2016 to 2019, natural gas power plant is the least-cost option to help reduce $\mathrm{CO}_{2}$ emissions. However, in 2020, the cost of wind power becomes slightly lower than natural gas. Thus, the combination of technologies-natural gas (from 2016 to 2019) and wind power (2020) is the least cost strategy and total cost is 1.00 billion dollars. 


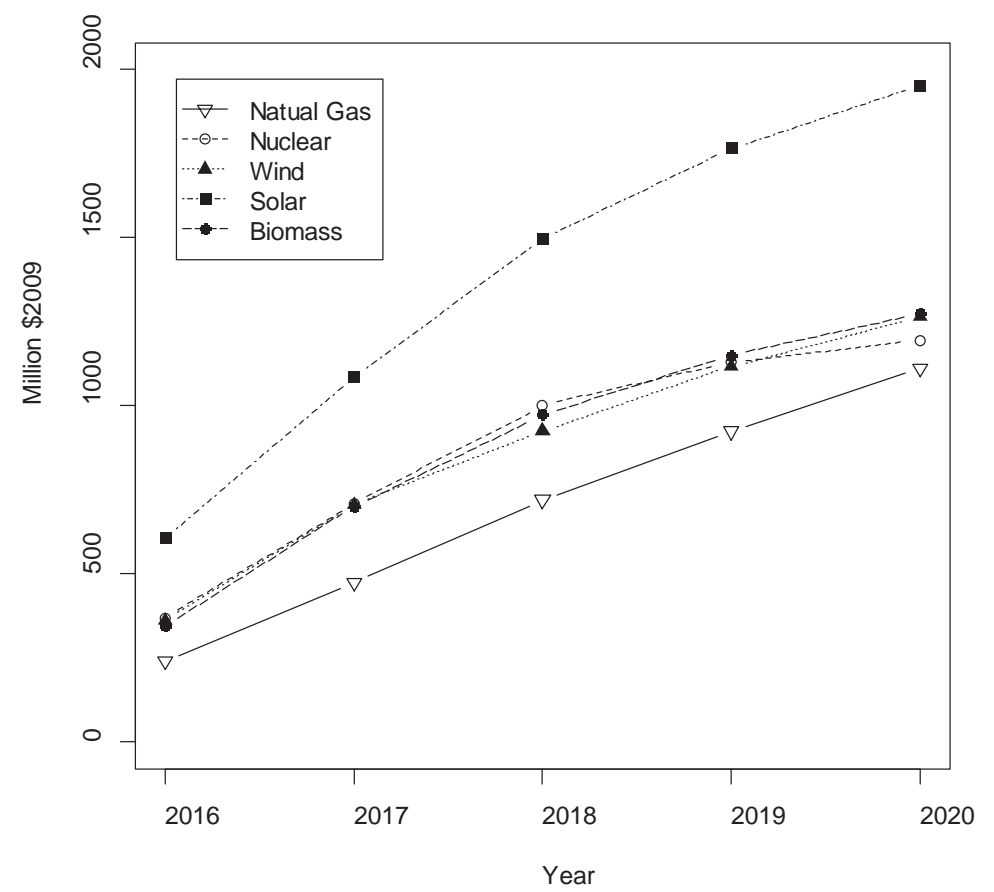

Figure 21: Total Cost of $\mathrm{CO}_{2}$ Emission Reduction Technologies under the 50\% Scenario (The Current PTCs for Wind and Biomass will not Change after 2015 and the Cost of Intermittency is Included).

In the $50 \%$ scenario, the natural gas is best candidate to replace coal to generate electricity for $\mathrm{CO}_{2}$ emission reduction. Compared with wind power and biomass energy, the cost of nuclear energy has a slow increase rate. Although the costs of these three technologies are very close in 2016, 2017 and 2019, the cost of nuclear becomes somewhat lower in 2020. 


\section{Chapter 6 Conclusion}

This thesis attempts to investigate the possible impacts of the EPA's proposed $\mathrm{CO}_{2}$ regulation on existing coal-fired power plants by estimating and comparing the costs of $\mathrm{CO}_{2}$ mitigation technologies in Michigan. The ultimate goal is to find the least-cost strategy to help electricity providers reduce $\mathrm{CO}_{2}$ emission under the proposed standards. An ARIMA model was built to forecast coal consumption for electricity generation from 2016 to 2020 in Michigan. Then this thesis calculated the cost of reducing $\mathrm{CO}_{2}$ emissions by replacing coal by other energy sources under three emission reduction scenariosreduction to $17 \%, 30 \%$ and $50 \%$ below the 2005 emission level. The impacts of PTCs for wind and biomass power plants are discussed in this thesis, despite the uncertainty of whether or not the current PTC policies for these two sources of power will continue. Also, the influence of intermittency of renewable energy resources on the total cost is also examined. The major findings of this study are shown in Table 14.

Based on the forecast in this thesis, the $\mathrm{CO}_{2}$ emissions from coal-fired power plants in 2016 will be $17 \%$ lower than their 2005 emission level in the business as usual scenario. Thus, it is not surprising to find that the cost of $\mathrm{CO}_{2}$ reduction under the $17 \%$ emission reduction scenario is zero. In most of the scenarios, replacing coal by natural gas is the most cost-effective way to reduce $\mathrm{CO}_{2}$ emission in Michigan electric power sector, even though the cost of $\mathrm{CO}_{2}$ emission standards on new natural gas power plants have been included. If the current PTC for wind power plants continues from 2016 to 2020, in specific years the $\mathrm{CO}_{2}$ mitigation cost of using wind power for electricity 
Table 14: Cost Ranges of $\mathrm{CO}_{2}$ Emission Reduction and Least-cost Strategies (2009\$)

\begin{tabular}{|c|c|c|c|c|}
\hline \multicolumn{5}{|c|}{$17 \%$ Scenario } \\
\hline $\begin{array}{c}\text { Cost of } \\
\text { Intermittency }\end{array}$ & $\mathrm{N}$ & $\mathrm{N}$ & I & I \\
\hline $\begin{array}{c}\text { PTCs for Wind \& } \\
\text { Biomass }\end{array}$ & $\mathrm{N}$ & I & $\mathrm{N}$ & I \\
\hline Lower Range & 0 & 0 & 0 & 0 \\
\hline Upper Range & 0 & 0 & 0 & 0 \\
\hline $\begin{array}{l}\text { Least-cost } \\
\text { Strategy }\end{array}$ & l & I & l & l \\
\hline \multicolumn{5}{|c|}{$30 \%$ Scenario } \\
\hline $\begin{array}{c}\text { Cost of } \\
\text { Intermittency } \\
\end{array}$ & $\mathrm{N}$ & $\mathrm{N}$ & I & I \\
\hline $\begin{array}{l}\text { PTCs for Wind \& } \\
\text { Biomass }\end{array}$ & $\mathrm{N}$ & I & $\mathrm{N}$ & I \\
\hline Lower Range & $1.01 \mathrm{~B}$ & $921.17 \mathrm{M}$ & $1.01 \mathrm{~B}$ & $1.00 \mathrm{~B}$ \\
\hline Upper Range & $1.95 \mathrm{~B}$ & $1.95 \mathrm{~B}$ & $2.01 \mathrm{~B}$ & $2.01 \mathrm{~B}$ \\
\hline $\begin{array}{l}\text { Least-cost } \\
\text { Strategy }\end{array}$ & $\begin{array}{l}\text { Natural } \\
\text { Gas }\end{array}$ & $\begin{array}{l}\text { 2016-17: } \\
\text { Natural Gas } \\
\text { 2018-20: } \\
\text { Wind }\end{array}$ & $\begin{array}{l}\text { Natural } \\
\text { Gas }\end{array}$ & $\begin{array}{l}\text { 2016-19: } \\
\text { Natural Gas } \\
\text { 2020: Wind }\end{array}$ \\
\hline \multicolumn{5}{|c|}{$50 \%$ Scenario } \\
\hline $\begin{array}{c}\text { Cost of } \\
\text { Intermittency }\end{array}$ & $\mathrm{N}$ & $\mathrm{N}$ & I & I \\
\hline $\begin{array}{l}\text { PTCs for Wind \& } \\
\text { Biomass } \\
\end{array}$ & $\mathrm{N}$ & I & $\mathrm{N}$ & I \\
\hline Lower Range & $3.47 \mathrm{~B}$ & $3.16 \mathrm{~B}$ & $3.47 \mathrm{~B}$ & $3.47 \mathrm{~B}$ \\
\hline Upper Range & $6.71 \mathrm{~B}$ & $6.71 \mathrm{~B}$ & $6.91 \mathrm{~B}$ & $6.91 \mathrm{~B}$ \\
\hline $\begin{array}{l}\text { Least-cost } \\
\text { Strategy }\end{array}$ & $\begin{array}{l}\text { Natural } \\
\text { Gas }\end{array}$ & $\begin{array}{l}\text { 2016-17: } \\
\text { Natural Gas } \\
\text { 2018-20: } \\
\text { Wind }\end{array}$ & $\begin{array}{l}\text { Natural } \\
\text { Gas }\end{array}$ & $\begin{array}{l}\text { Natural } \\
\text { Gas }\end{array}$ \\
\hline
\end{tabular}

Source: Author's calculation.

Note: "N" and "I" represents "Not Included" and "Included"; "M" and "B" means "million" and "billion", respectively. 
generation becomes lower than advanced-combined-cycle natural gas power plants. In this situation, a combination strategy is regarded as the least-cost option for $\mathrm{CO}_{2}$ reduction.

The results of the analysis strongly recommend that electricity providers that generating electricity from natural gas should be regarded as the primary choice to achieve $\mathrm{CO}_{2}$ emission reduction targets under both the $30 \%$ and $50 \%$ reduction scenarios based on the least-cost criterion. If the cost of intermittency of renewable energy is considered in either $30 \%$ or $50 \%$ scenario, building natural gas power plants is still the best $\mathrm{CO}_{2}$ mitigation strategy to realize $\mathrm{CO}_{2}$ emission reduction goal. However, if the current PTC for wind power plants will continue after 2015, even taking the intermittence of wind power into account, wind power plants replace natural gas power plants and becomes the least cost technology to reduce $\mathrm{CO}_{2}$ emission in the future. In this situation, it is suggested that utilities should generate electricity from natural gas power plants in the initial two years and turn to wind power technology from 2018 to 2020 if not considering the impact of intermittency of wind power; when thinking of the cost of intermittency, the cost-effective plan is generating electricity from natural gas from 2016 to 2019 and from wind power in 2020.

This thesis analyzed the cost of $\mathrm{CO}_{2}$ emission reduction for coal power plants from 2016 to 2020 based on some important assumptions. Also, one should be cautious about the limitations of this study when using the results of this thesis. The limitations of this study originate from two aspects: the insufficiency of the forecast model and the accuracy of the energy cost estimates. 
The ARIMA model, which was built to forecast future coal consumption for electricity generation in Michigan, is based on Box-Jenkins methodology. Some scholars argue against the accuracy of the forecasting results by using this approach. The most common criticism stems from the integrated part of the model. Makridakisand and Hibon (1997) argue that differencing the data to have a stationary mean is the major problem. Based on some empirical examples, the accuracy of a simple time series method can be better than ARIMA model. In this study, a linear regression model is initially established to check whether or not a simple model can generalize most of the information of the data. However, the results are less than satisfactory. Definitely, one can test the accuracy of other simple approaches, which are not mentioned in this thesis. It is possible that some simple model can make more accurate forecast than can the ARIMA model.

Also, not only can differencing lose one observation each time, but also unnecessary correlations can be introduced by overdifferencing, which makes the modeling process more complicated (Cryer and Chan 2008). The final model in this thesis is ARIMA $(0,2,1)$, which is differenced twice to achieve a stationary mean. Based on the $\mathrm{ACF}$ of the second difference of the original time series data in Figure 5, differencing the data twice does not introduce serious correlations (except lag 1). Thus, it is assumed that the there is no negative impacts from differencing in this model.

One can argue that the residuals of ARIMA $(0,2,1)$ (see Figure 8) are a little heteroskedastic and some of residuals on the right tail of the Q-Q plot (see Figure 9) are somewhat wandering off. Both of these shortcomings may reflect that the final model is not perfect. 
The other limitation of this study is applying the LCE approach to calculating the cost of electricity generation from different sources. For Michigan, LCE data are not available, the thesis uses the national average figure for approximation. As noted in EIA's levelized cost of new generation resources in the Annual Energy Outlook, the costs of non-dispatchable technologies vary by region significantly. It is possible that a big difference exists between Michigan figures and the national average figures, which would greatly influence the results in this thesis. Future studies on the same topic can make more precise estimation if the LCE in Michigan can be acquired.

Moreover, this thesis cannot answer the question what impacts are on the price and supply of natural gas in Michigan if the utilities replace large quantity of coal by natural gas for power generation to reduce $\mathrm{CO}_{2}$ emissions based on suggestions in this study. It is possible that using more natural gas in the power plants can cause an increase in natural gas price. Thus, building natural gas power plants would not be the least coast strategy for $\mathrm{CO}_{2}$ emission reduction in some scenarios.

Also, this thesis assumes that the electricity providers will build new power plants to replace electricity generation from coal. For some power plants, the capacity investment accounts for the major cost of generating electricity. It is likely that utilities prefer using the existing electric capacity instead of investing in new ones to minimize cost. However, it is uncertain whether or not the current electric capacity is enough for generating extra electricity. This question can be solved by fully studying Michigan's electric system via engineering approaches, which is out of the scope of this thesis. 
The methods and the reasoning procedures in this thesis can contribute to the future studies and research on similar topics in other states. Although it is impossible to reduce $\mathrm{CO}_{2}$ emission to $30 \%$ and $50 \%$ below 2005 emission level in a short period of time, this study provides cost ranges of $\mathrm{CO}_{2}$ emission reduction by generating electricity from low carbon energy sources instead of coal. The results in this study can be applied to compare with the costs of other $\mathrm{CO}_{2}$ mitigation strategies, such as increasing the efficiency of existing coal-fired power plants, to help utility regulators make wise $\mathrm{CO}_{2}$ emission reduction plans in Michigan. 


\section{References}

American Lung Association (2011). Toxic Air: Time to Clean Up Coal-fired Power Plants. Chicago, IL, U.S. http://www.lung.org/assets/documents/healthy-air/toxic-airreport.pdf; http://www.lung.org/assets/documents/healthy-air/supplemental-table-ofpower.pdf, retrieve on April 1 ${ }^{\text {st }}, 2014$.

Abdel-Aal, R. E., \& Al-Garni, A. Z. (1997). Forecasting monthly electric energy consumption in eastern Saudi Arabia using univariate time-series analysis. Energy, 22(11), 1059-1069.

Azadeh, A., S. F. Ghaderi, and S. Sohrabkhani. "A simulated-based neural network algorithm for forecasting electrical energy consumption in Iran." Energy Policy 36, no. 7 (2008): 2637-2644.

Box, George EP, Gwilym M. Jenkins, and Gregory C. Reinsel. Time series analysis: forecasting and control. John Wiley \& Sons, 2013.

Crane, K., Curtright, A. E., Ortiz, D. S., Samaras, C., \& Burger, N. (2011). The economic costs of reducing greenhouse gas emissions under a US national renewable electricity mandate. Energy Policy, 39(5), 2730-2739.

Cryer, J. D., \& Chan, K. S. (2008). Time series analysis with applications in R. Springer.

DeCarolis, J. F., \& Keith, D. W. (2005). The costs of wind's variability: is there a threshold?. The Electricity Journal, 18(1), 69-77.

Dickey, D. A., \& Fuller, W. A. (1979). Distribution of the estimators for autoregressive time series with a unit root. Journal of the American statistical association, 74(366a), 427-431.

DSIRE. 2013. "Renewable Electricity Production Tax Credit (PTC)". Retrieved from http://dsireusa.org/incentives/incentive.cfm?Incentive_Code=US13F on April 11th, 2014.

Durbin, J., \& Watson, G. S. (1971). "Testing for serial correlation in least squares regression.III". Biometrika 58 (1): 1-19.

Executive Office of the President, June 2013, The President's Climate Action Plan, http://www.whitehouse.gov/sites/default/files/image/president27sclimateactionplan.pdf, retrieved on January $10^{\text {th }}, 2014$.

EPA. 2013. "Considerations in the Design of a Program to Reduce Carbon Pollution from Existing Power Plants". Washington, DC: U.S.A. EPA. 
See http://www2.epa.gov/sites/production/files/201309/documents/20130923statequestions.pdf, retrieved on Jan 11 ${ }^{\text {th }}, 2014$.

EPA. 2013. "Inventory of U.S. Greenhouse Gas Emissions and Sinks: 1990-2011". Washington, DC: U.S.A. EPA.

EPA. 2013. "Standards of Performance for Greenhouse Gas Emissions From New Stationary Sources: Electric Utility Generating Units" Retrieved from http://www.gpo.gov/fdsys/pkg/FR-2014-01-08/pdf/2013-28668.pdf on April 11th, 2014.

EPA. 2013. "EPA Fact Sheet: Reducing Carbon Pollution from Power Plants" Retrieved from http://www.gpo.gov/fdsys/pkg/FR-2014-01-08/pdf/2013-28668.pdf on April 11th, 2014.

Epstein, P. R., Buonocore, J. J., Eckerle, K., Hendryx, M., Stout III, B. M., Heinberg, R., Clapp, R. W., May, B., Reinhart, N. L., Ahern, M. M., Doshi, S. K.\& Glustrom, L. (2011). Full Cost Accounting for the Life Cycle of Coal. Annals of the New York Academy of Sciences, 1219(1), 73-98.

EIA's FREQUENTLY ASKED QUESTIONS website, http://www.eia.gov/tools/faqs/faq.cfm?id=74\&t=11, retrieved on March 30 $0^{\text {th }}, 2014$.

EIA "FREQUENTLY ASKED QUESTIONS- How much coal, natural gas, or petroleum is used to generate a kilowatthour of electricity?", retrieved on April 10th, 2014.

EIA. 2011b. "Levelized Cost of New Generation Resources in the Annual Energy Outlook 2011". Washington, DC: U.S. EIA.

EIA. 2012b. "Levelized Cost of New Generation Resources in the Annual Energy Outlook 2011". Washington, DC: U.S. EIA.

EIA. 2013b. "Levelized Cost of New Generation Resources in the Annual Energy Outlook 2011". Washington, DC: U.S. EIA.

EIA. 2014b. "Levelized Cost of New Generation Resources in the Annual Energy Outlook 2011". Washington, DC: U.S. EIA.

EIA. Electric Power Annual. Table 1.1. Total electric power industry summary statistics. Washington, DC: U.S. EIA. See on http://www.eia.gov/electricity/annual/, retrieved on Jan $10^{\text {th }}, 2014$.

EIA. Today In Energy. Washington, DC: U.S. EIA. See http://www.eia.gov/todayinenergy/detail.cfm?id=14291, retrieved on Jan 11 ${ }^{\text {th }}, 2014$. 
EIA. Table 5 in Michigan Electricity Profile. See http://www.eia.gov/electricity/state/michigan/, retrieved on Jan $8^{\text {th }}, 2014$.

EIA. Table 7 in Michigan Electricity Profile. See http://www.eia.gov/electricity/state/michigan/, retrieved on Jan $8^{\text {th }}, 2014$.

Fischer, C., \& Newell, R. G. (2008). Environmental and technology policies for climate mitigation. Journal of environmental economics and management, 55(2), 142-162.

Gowrisankaran, G., Reynolds, S. S., \& Samano, M. (2011). Intermittency and the value of renewable energy (No. w17086). National Bureau of Economic Research.

Gibbins, J., \& Chalmers, H. (2008). Carbon capture and storage. Energy Policy, 36(12), 4317-4322.

Gustavsson, Leif, Jonas Holmberg, Veronica Dornburg, Roger Sathre, Thies Eggers, Krushna Mahapatra, and Gregg Marland. "Using biomass for climate change mitigation and oil use reduction." Energy policy 35, no. 11 (2007): 5671-5691

Hagan, Martin T., and Suzanne M. Behr. "The time series approach to short term load forecasting." Power Systems, IEEE Transactions on 2, no. 3 (1987): 785-791.

IPCC, 2005. IPCC Special Report on Carbon Dioxide Capture and Storage. Prepared by Working Group III of the Intergovernmental Panel on Climate Change. Cambridge University Press, Cambridge, UK, New York, NY, USA.

IPCC AR4 WG1 (2007), Climate Change 2007: The Physical Science Basis, Contribution of Working Group I to the Fourth Assessment Report of the Intergovernmental Panel on Climate Change Climate Change. Cambridge University Press, Cambridge, United Kingdom and New York, NY, USA.

IPCC AR5 WG1 (2013), Climate Change 2013: The Physical Science Basis, Contribution of Working Group I to the Fifth Assessment Report of the Intergovernmental Panel on Climate Change Climate Change.

Ljung, Greta M., and George EP Box. "On a measure of lack of fit in time series models." Biometrika 65, no. 2 (1978): 297-303.

Lopez, A., Roberts, B., Heimiller, D., Blair, N., \& Porro, G. (2012). US Renewable Energy Technical Potentials: A GIS-Based Analysis (NO.NREL/TP-6A20-51946A). Golden, CO, U.S.: National Renewable Energy Laboratory. Retrieved from: http://blogsimages.forbes.com/davidferris/files/2012/08/51946.pdf. 
Makridakis, Spyros, and Michele Hibon. "ARMA models and the Box-Jenkins methodology." Journal of Forecasting 16, no. 3 (1997): 147-163.

Mohamed, Z., \& Bodger, P. (2005). Forecasting electricity consumption in New Zealand using economic and demographic variables. Energy, 30(10), 1833-1843.

Pappas, S. S., Ekonomou, L., Karamousantas, D. C., Chatzarakis, G. E., Katsikas, S. K., \& Liatsis, P. (2008). Electricity demand loads modeling using AutoRegressive Moving Average (ARMA) models. Energy, 33(9), 1353-1360.

Roth, I. F. and L. L. Ambs (2004). Incorporating Externalities into a Full Cost Approach to Electric Power Generation Life-Cycle Costing. Energy 29(12): 2125-2144.

Rubin, E. S., Chen, C., \& Rao, A. B. (2007). Cost and performance of fossil fuel power plants with $\mathrm{CO}<\mathrm{sub}>2</$ sub $>$ capture and storage. Energy Policy, 35(9), 4444-4454.

Sailor, W. C., Bodansky, D., Braun, C., Fetter, S., \& van der Zwaan, B. (2000). A nuclear solution to climate change?. Science(Washington), 288(5469), 1177-1178.

Smith, J. C., DeMeo, E. A., Parsons, B., \& Milligan, M. (2004). Wind Power Impacts on Electric Power System Operating Costs: Summary and Perspective on Work to Date; Preprint (No. NREL/CP-500-35946). National Renewable Energy Lab., Golden, CO.(US).

Sims, R. E., Rogner, H. H., \& Gregory, K. (2003). Carbon emission and mitigation cost comparisons between fossil fuel, nuclear and renewable energy resources for electricity generation. Energy policy, 31(13), 1315-1326.

Sovacool, B. K. (2009). The intermittency of wind, solar, and renewable electricity generators: Technical barrier or rhetorical excuse?. Utilities Policy, 17(3), 288-296.

Worrell, Ernst, Lenny Bernstein, Joyashree Roy, Lynn Price, and Jochen Harnisch. "Industrial energy efficiency and climate change mitigation." Energy Efficiency 2, no. 2 (2009): 109-123.

White House. 2013. "Presidential Memorandum -- Power Sector Carbon Pollution Standards". Washington, DC: U.S. White House.

Yao, Albert WL, S. C. Chi, and J. H. Chen. "An improved grey-based approach for electricity demand forecasting." Electric Power Systems Research 67, no. 3 (2003): 217224.

Zhou, P., B. W. Ang, and K. L. Poh. "A trigonometric grey prediction approach to forecasting electricity demand." Energy 31, no. 14 (2006): 2839-2847. 


\section{Appendices}

Appendix A: Coal Consumption for Electricity Generation from 1960 to 2011 in Michigan

Table A1: Coal Consumption for Electricity Generation from 1960 to 2011 in Michigan

\begin{tabular}{|c|c|c|c|}
\hline Year & $\begin{array}{c}\text { Coal } \\
\text { (Trillion Btu) }\end{array}$ & Year & $\begin{array}{c}\text { Coal } \\
\text { (Trillion Btu) }\end{array}$ \\
\hline 1960 & 256.3 & 1986 & 634.4 \\
\hline 1961 & 255.1 & 1987 & 713.6 \\
\hline 1962 & 298.5 & 1988 & 696 \\
\hline 1963 & 329.6 & 1989 & 667 \\
\hline 1964 & 359.7 & 1990 & 663.5 \\
\hline 1965 & 399.9 & 1991 & 665.1 \\
\hline 1966 & 457.5 & 1992 & 626.5 \\
\hline 1967 & 478 & 1993 & 631.4 \\
\hline 1968 & 519 & 1994 & 686.7 \\
\hline 1969 & 541.7 & 1995 & 671.2 \\
\hline 1970 & 487 & 1996 & 682.1 \\
\hline 1971 & 496.1 & 1997 & 681.4 \\
\hline 1972 & 497.4 & 1998 & 725.3 \\
\hline 1973 & 494.2 & 1999 & 712.2 \\
\hline 1974 & 488.4 & 2000 & 694.7 \\
\hline 1975 & 494.9 & 2001 & 690.5 \\
\hline 1976 & 482.6 & 2002 & 660.8 \\
\hline 1977 & 495.5 & 2003 & 672.6 \\
\hline 1978 & 496.5 & 2004 & 691.2 \\
\hline 1979 & 546.5 & 2005 & 718.2 \\
\hline 1980 & 532.2 & 2006 & 693.4 \\
\hline 1981 & 549.8 & 2007 & 721.3 \\
\hline 1982 & 521.3 & 2008 & 712.4 \\
\hline 1983 & 534.2 & 2009 & 682.5 \\
\hline 1984 & 571.6 & 2010 & 677.6 \\
\hline 1985 & 605.8 & 2011 & 620.4 \\
\hline & & & \\
\hline
\end{tabular}


Appendix B: The Linear Regression Results of Coal Consumption against Year from Using the $R$ Program

Call:

$\operatorname{lm}($ formula $=$ consumption $\sim \mathrm{t})$

Residuals:

Min 1Q Median 3Q Max

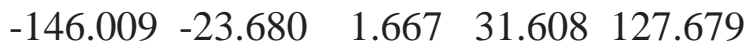

Coefficients:

Estimate Std. Error t value $\operatorname{Pr}(>|t|)$

(Intercept) $375.3518 \quad 16.0881 \quad 23.33<2 \mathrm{e}-16 * * *$

t $\quad 7.5203 \quad 0.5283 \quad 14.24<2 \mathrm{e}-16 * * *$

$---$

Signif. codes: 0 ‘***’ 0.001 '**’ 0.01 '*’ 0.05 ‘' 0.1 “ ' 1

Residual standard error: 57.17 on 50 degrees of freedom

Multiple R-squared: 0.8021, Adjusted R-squared: 0.7982

F-statistic: 202.7 on 1 and $50 \mathrm{DF}$, p-value: <2.2e-16 
Appendix C: Residual Plot Against the Independent Variable from the Linear Regression Approach

Figure A1: Residual Plot Against the Independent Variable from the Linear Regression Approach

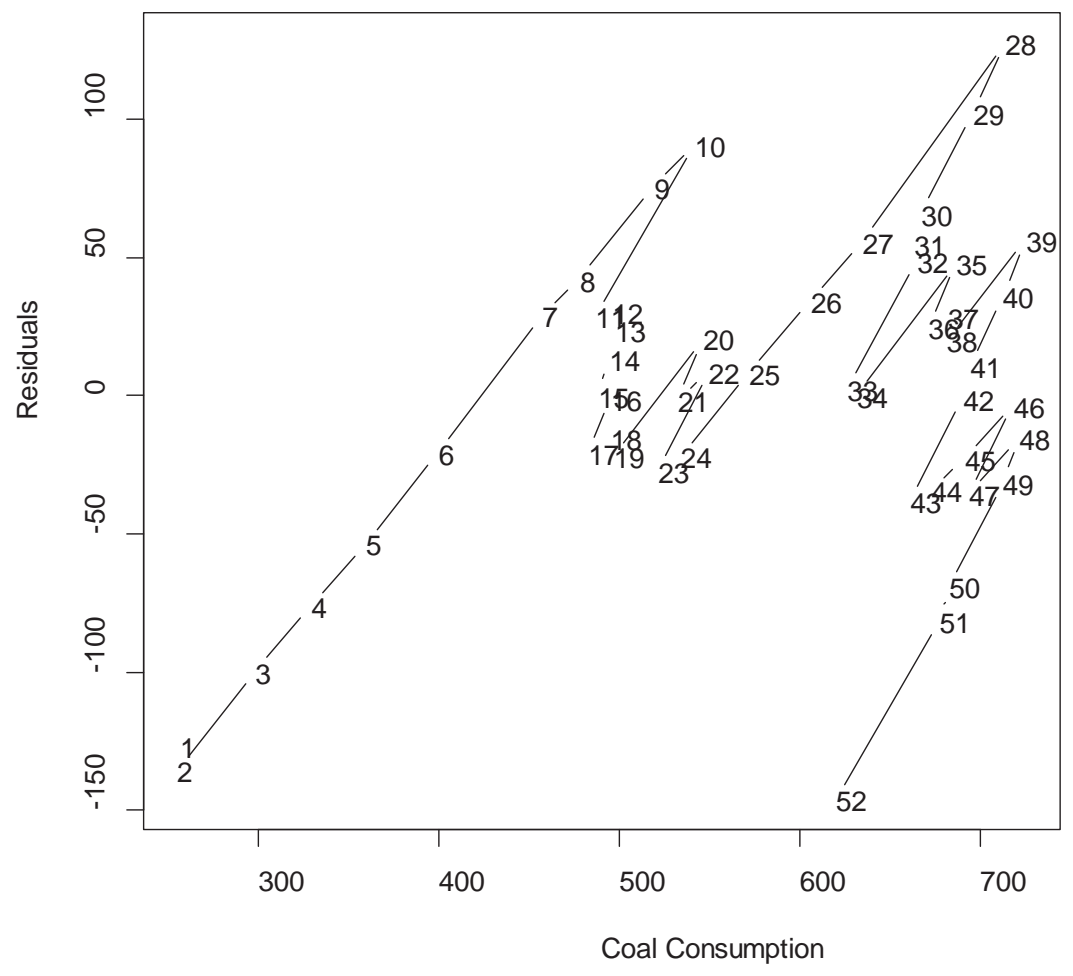


Appendix D: Q-Q Plot for the Residuals of Linear Regression Approach

Figure A2: Q-Q Plot for the Residuals of Linear Regression Approach

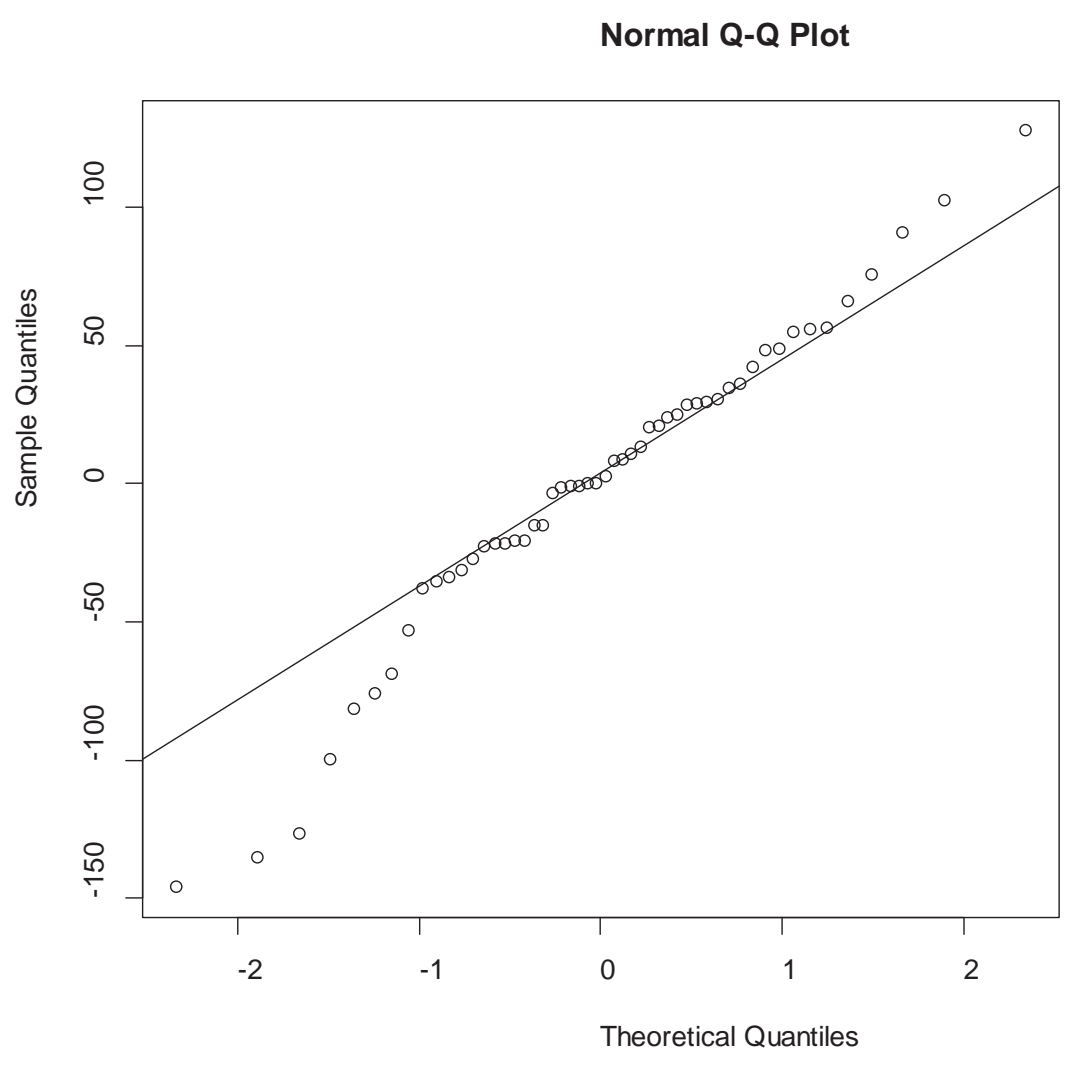




\section{Appendix E: The R Outputs of Durbin-Waton Test for the Residuals of the Linear Regression Approach}

\begin{tabular}{llll}
\multicolumn{5}{l}{ lag } & Autocorrelation & D-W Statistic & p-value \\
1 & 0.7922468277 & 0.1652762 & 0.000 \\
2 & 0.5650104192 & 0.4003861 & 0.000 \\
3 & 0.3626701852 & 0.6995635 & 0.000 \\
4 & 0.1817266364 & 1.0129067 & 0.000 \\
5 & 0.0283205356 & 1.3000105 & 0.062 \\
6 & -0.0682106101 & 1.4844298 & 0.220 \\
7 & -0.1002996112 & 1.5388353 & 0.378 \\
8 & -0.1245178899 & 1.5687102 & 0.554 \\
9 & -0.1009631457 & 1.4793590 & 0.404 \\
10 & -0.0641832454 & 1.3511096 & 0.282 \\
11 & -0.0688906813 & 1.3511055 & 0.302 \\
12 & -0.0654606135 & 1.3342687 & 0.362 \\
13 & -0.0516896089 & 1.2969253 & 0.362 \\
14 & -0.0339195014 & 1.2505636 & 0.372 \\
15 & -0.0278413113 & 1.2359721 & 0.368 \\
16 & -0.0119287651 & 1.2005294 & 0.342 \\
17 & -0.0064370471 & 1.1873522 & 0.434 \\
18 & 0.0141016401 & 1.1389306 & 0.462 \\
19 & -0.0005383361 & 1.1679815 & 0.608 \\
20 & -0.0176500126 & 1.1957020 & 0.790 \\
Alternative hypothesis: rho[lag] & $!=0$
\end{tabular}


Appendix F: Sample ACF for the Standardized Residuals of the Linear Regression Model

Figure A3: Sample ACF for the Standardized Residuals of the Linear Regression Model

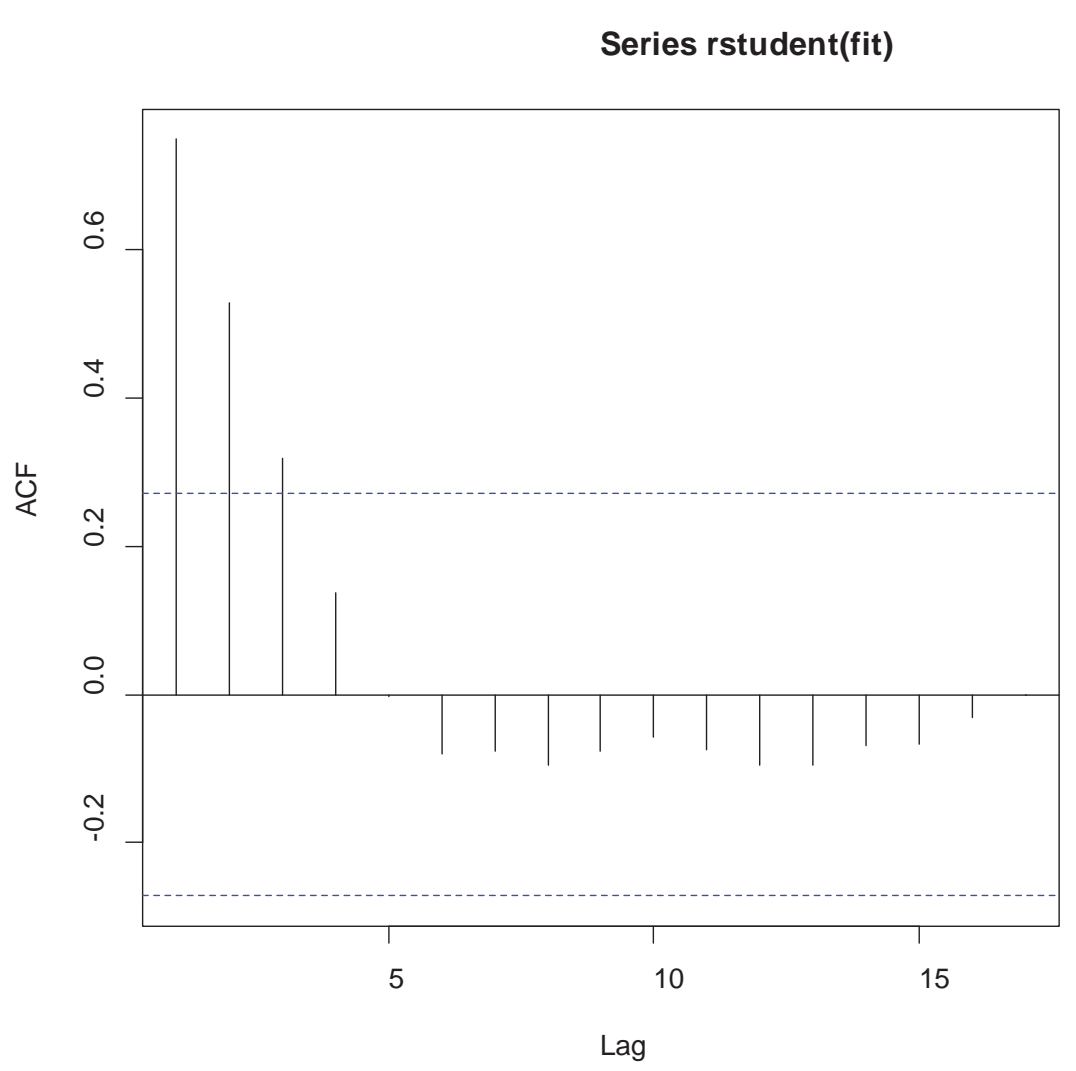


Appendix G: The R Outputs of Dickey-Fuller Test of the Fist difference of Coal Consumption for Electricity Generation in Michigan

Augmented Dickey-Fuller Test

data: coal.diff

Dickey-Fuller $=-3.1324$, Lag order $=3$, p-value $=0.1191$

alternative hypothesis: stationary

Appendix H: The R Outputs of Durbin-Waton Unit Root Test of the Second Difference of Coal Consumption for Electricity Generation in Michigan

Augmented Dickey-Fuller Test

data: coal.diff2

Dickey-Fuller $=-3.7986$, Lag order $=3$, p-value $=0.02561$

alternative hypothesis: stationary

Appendix I: The R Outputs of Estimating the Parameters of ARIMA $(2,2,1)$ by Maximum Likelihood Method

Series: $\mathrm{x}$

$\operatorname{ARIMA}(2,2,1)$

Coefficients:

ar1 ar2 ma1 xreg

$\begin{array}{llll}0.0683 & 0.1152 & -0.9241 & 18.2447\end{array}$

s.e. $0.1606 \quad 0.1562 \quad 0.0761 \quad 28292.5527$

sigma $^{\wedge} 2$ estimated as 835.9: $\log$ likelihood $=-239.96$

$\mathrm{AIC}=487.92 \quad \mathrm{AICc}=489.29 \quad \mathrm{BIC}=497.48$ 
Appendix J: The R Outputs of Estimating the Parameters of ARIMA $(0,2,1)$ by Maximum Likelihood Method

Series: $\mathrm{x}$

$\operatorname{ARIMA}(0,2,1)$

Coefficients:

ma1 xreg

$-0.890618 .2447$

s.e. $0.0872 \mathrm{NaN}$

sigma^$^{\wedge} 2$ estimated as 847.4: $\log$ likelihood $=-240.29$

$\mathrm{AIC}=484.58 \quad \mathrm{AICc}=485.1 \quad \mathrm{BIC}=490.32$

Appendix K: The R Outputs of the auto.arima Function to Find the Appropriate ARIMA Model

Series: consumption

$\operatorname{ARIMA}(0,2,1)$

Coefficients:

ma1

$-0.8907$

s.e. 0.0871

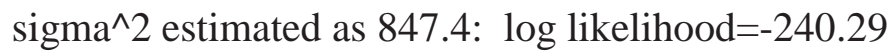

$\mathrm{AIC}=484.58 \quad \mathrm{AICc}=484.83 \quad \mathrm{BIC}=488.4$

Appendix L: The R outputs of Box-Ljung Test for the Residuals of ARIMA $(0,2,1)$ Model

Box-Ljung test

data: data.fit1\$residual

X-squared $=0.0122, \mathrm{df}=1, \mathrm{p}$-value $=0.9122$ 
Appendix M: The R Outputs of the Predicted Values, 95\% Prediction Intervals, and Standard Errors of Prediction

Table A2: The R Outputs of the Predicted Values, 95\% Prediction Intervals, and Standard Errors of Prediction

\begin{tabular}{|c|c|c|c|c|}
\hline Year & $\begin{array}{c}\text { Coal } \\
\text { Consumption } \\
\text { (Trillion Btu) }\end{array}$ & $\begin{array}{c}\text { The Lower } \\
\text { Prediction } \\
\text { Intervals } \\
\text { (Trillion } \\
\text { Btu) }\end{array}$ & $\begin{array}{c}\text { The Upper } \\
\text { Prediction } \\
\text { Intervals } \\
\text { (Trillion } \\
\text { Btu) }\end{array}$ & $\begin{array}{c}\text { Standard } \\
\text { Errors }\end{array}$ \\
\hline $\mathbf{2 0 1 2}$ & 613.880 & 556.823 & 670.936 & 29.110 \\
\hline $\mathbf{2 0 1 3}$ & 607.360 & 522.142 & 692.577 & 43.478 \\
\hline $\mathbf{2 0 1 4}$ & 600.839 & 490.850 & 710.829 & 56.117 \\
\hline $\mathbf{2 0 1 5}$ & 594.319 & 460.752 & 727.886 & 68.147 \\
\hline $\mathbf{2 0 1 6}$ & 587.799 & 431.058 & 744.539 & 79.970 \\
\hline $\mathbf{2 0 1 7}$ & 581.278 & 401.396 & 761.161 & 91.777 \\
\hline $\mathbf{2 0 1 8}$ & 574.758 & 371.563 & 777.954 & 103.671 \\
\hline $\mathbf{2 0 1 9}$ & 568.238 & 341.439 & 795.037 & 115.714 \\
\hline $\mathbf{2 0 2 0}$ & 561.718 & 310.952 & 812.483 & 127.942 \\
\hline
\end{tabular}

